\title{
A multi-pronged comparative study of the ultraviolet photochemistry of 2-, 3- and 4-chlorophenol in the gas phase
}

S.J. Harris, T.N.V. Karsili, D. Murdock, T.A.A. Oliver, ${ }^{\#}$ A.M. Wenge, ${ }^{\#}$ D.K. Zaouris, ${ }^{\# \#}$ M.N.R. Ashfold and J.N. Harvey, School of Chemistry, University of Bristol, BS8 1TS, U.K.

J.D. Few, S. Gowrie and G. Hancock, Department of Chemistry, Physical and Theoretical Chemistry Laboratory, Oxford University, South Parks Road, Oxford OX1 3QZ, U.K.

D.J. Hadden, G.M. Roberts and V.G. Stavros, Department of Chemistry, University of Warwick, Coventry CV4 7AL, U.K.

G. Spighi, L. Poisson and B. Soep, CNRS, IRAMIS, SPAM, Laboratoire Francis Perrin, URA 2453, F-91191 Gif-sur-Yvette, France.

No. of Tables: $\quad 1$

No. of figures: $\quad 10$

Current addresses:

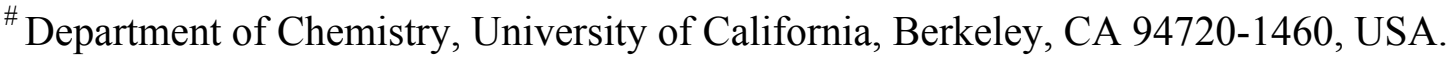

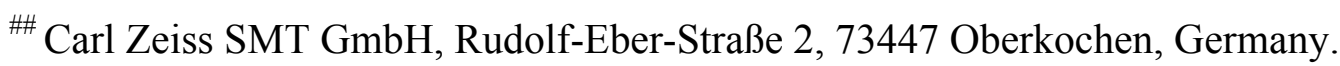

\#\#\# Institute of Electronic Structure and Laser (IESL), Foundation for Research and Technology - Hellas (FORTH), P.O. Box 1527, GR-71110 Heraklion, Greece.

Abstract 
The $\mathrm{S}_{1}\left({ }^{1} \pi \pi^{*}\right)$ state of the (dominant) syn-conformer of 2-chlorophenol (2-ClPhOH) in the gas phase has a sub-picosecond lifetime, whereas the corresponding $\mathrm{S}_{1}$ states of 3- and 4-ClPhOH have lifetimes that are, respectively, $\sim 2$ and $\sim 3$-orders of magnitude longer. A range of experimental techniques - electronic spectroscopy, ultrafast time-resolved photoion and photoelectron spectroscopies, H Rydberg atom photofragment translational spectroscopy, velocity map imaging and time-resolved Fourier transform infrared emission spectroscopy as well as electronic structure calculations (of key regions of the multidimensional ground $\left(\mathrm{S}_{0}\right)$ state potential energy surface (PES) and selected cuts through the first few excited singlet PESs) have been used in the quest to explain these striking differences in excited state lifetime. The intramolecular $\mathrm{O}-\mathrm{H}$--- $\mathrm{Cl}$ hydrogen bond specific to syn-2-ClPhOH is seen to be key. It encourages partial charge transfer and preferential stabilisation of the diabatic ${ }^{1} \pi \sigma^{*}$ potential (relative to that of the ${ }^{1} \pi \pi^{*}$ state) upon stretching the $\mathrm{C}-\mathrm{Cl}$ bond, with the result that initial $\mathrm{C}-\mathrm{Cl}$ bond extension on the adiabatic $\mathrm{S}_{1}$ PES offers an essentially barrierless internal conversion pathway via regions of conical intersection with the $\mathrm{S}_{0}$ PES. Intramolecular hydrogen bonding is thus seen to facilitate the type of heterolytic dissociation more typically encountered in solution studies. 


\section{Introduction}

The past decade has witnessed giant strides in our understanding of the primary photochemistry of gas phase phenols. ${ }^{1,2}$ These systems provide classic examples of dissociation by $\mathrm{O}-\mathrm{H}$ bond fission on an excited ${ }^{1} \pi \sigma^{*}$ potential energy surface (PES), as predicted by Sobolewski et al. ${ }^{3}$ The ground $\left(\mathrm{S}_{0}\right)$ state of phenol correlates diabatically with the excited $(\tilde{A})$ electronic state of the phenoxyl radical. The first excited ${ }^{1} \pi \pi^{*}$ state (traditionally labelled $\mathrm{S}_{1}$ ) and its triplet ${ }^{3} \pi \pi^{*}$ counterpart are bound with respect to $R_{\mathrm{O}-\mathrm{H}}$, but the diabatic ${ }^{1} \pi \sigma^{*}$ (henceforth $\mathrm{S}_{2}$ ) state and the corresponding ${ }^{3} \pi \sigma^{*}$ state are both repulsive upon extending $R_{\mathrm{O}-\mathrm{H}}$ and correlate with ground $(\widetilde{\mathrm{X}})$ state phenoxyl radical products. The $\mathrm{S}_{2}$ PES thus exhibits conical intersections (CIs) with the $\mathrm{S}_{1}$ state (at $R_{\mathrm{O}-\mathrm{H}} \sim 1.2 \AA$ ) and with the $\mathrm{S}_{0}$ PES at longer $R_{\mathrm{O}-\mathrm{H}}(\sim 2.1 \AA) .{ }^{4} \mathrm{O}-\mathrm{H}$ bond fission on the $\mathrm{S}_{2}$ PES is observed following ultraviolet (UV) excitation of phenol at its $\mathrm{S}_{1}-\mathrm{S}_{0}$ origin. Most of the energy in excess of that required to break the $\mathrm{O}-\mathrm{H}$ bond is released as product translational energy. The phenoxyl $(\widetilde{\mathrm{X}}$ ) products are formed rotationally 'cold' and in a limited sub-set of vibrational (v) states Systematic studies of the dissociation rates and product vibrational energy disposals following excitation to the $S_{1}$ state of phenol and a range of substituted phenols confirm that dissociation involves $\mathrm{H}$ atom tunnelling under the $\mathrm{S}_{1} / \mathrm{S}_{2} \mathrm{CI}{ }^{5}$ and that this process is facilitated by the $v_{16 \mathrm{a}}\left(a_{2}\right)$ ring puckering and/or $\mathrm{OH}$ torsion mode, depending on the molecular symmetry. ${ }^{4,6,7}$ Excitation at shorter wavelengths within the $\mathrm{S}_{1}-\mathrm{S}_{0}$ absorption system populates higher $\mathrm{S}_{1}(\mathrm{v})$ levels. This vibrational excitation tends to be in FranckCondon active parent modes that are orthogonal to the dissociation coordinate; such excitation contributes relatively little to the tunnelling process and tends to map through into product vibration. Excitation at yet shorter wavelengths, corresponding to energies above the $\mathrm{S}_{1} / \mathrm{S}_{2} \mathrm{CI}$ (typically $\sim 240 \mathrm{~nm}$ or shorter) allows direct access to the $\mathrm{S}_{2} \mathrm{PES}$, prompt $\mathrm{O}-\mathrm{H}$ bond fission and release of $\mathrm{H}$ atoms with much higher translational energy.

$\mathrm{O}-\mathrm{H}$ bond fission is just one of a number of dissociation routes possible on energetic grounds following UV excitation of phenols, however. Most photodissociation experiments focus on a particular product (e.g. $\mathrm{H}$ atom formation), though a combined experimental (time-resolved Fourier transform infrared (FTIR) emission spectroscopy) and ab initio theoretical study of alternative fragmentation pathways following $248 \mathrm{~nm}$ and $193 \mathrm{~nm}$ excitation of phenol and subsequent radiationless transfer to the $\mathrm{S}_{0}$ PES is a notable exception. ${ }^{8}$ 
Such complexity can be expected to increase upon extending to substituted phenols, as illustrated in the present work for the case of chlorophenols (henceforth $\mathrm{ClPhOH}$ ). These systems offer the possibility of additional dissociation pathways (e.g. $\mathrm{C}-\mathrm{Cl}$ versus $\mathrm{O}-\mathrm{H}$ bond fission, and possible $\mathrm{HCl}$ elimination) from excited states and/or on the ground state PES, at least some of which can be expected to display isomer specificity. 2- and 3-ClPhOH also both exist as syn- and anti-rotamers (often also termed cis- and trans-), reflecting the relative orientation of the $\mathrm{O}-\mathrm{H}$ bond to the $\mathrm{Cl}$ atom. In the case of $2-\mathrm{ClPhOH}$, the syn-rotamer is significantly stabilised by the intramolecular hydrogen bond between the hydroxyl $\mathrm{H}$ atom and the adjacent $\mathrm{Cl}$ atom (ref. 13) summarises various prior studies indicating that this rotamer is $\sim 570 \mathrm{~cm}^{-1}$ more stable than the anti-rotamer). Jet-cooled $\mathrm{S}_{1}-\mathrm{S}_{0}$ spectra have been reported for all three isomers. ${ }^{9-16}$ Each displays structure, but these studies already point to dramatic isomer-specific variations in $\mathrm{S}_{1}$ state lifetimes $\left(1.0 \pm 0.3 \mathrm{~ns}\right.$ for $4-\mathrm{ClPhOH},{ }^{17} c f$. estimates of $\tau \sim 0.3 \mathrm{ps}$ in the case of $s y n-2-\mathrm{ClPhOH}^{13}$ ).

Unsurprisingly, given their toxicity and ubiquity in aquatic systems, the aqueous phase photochemistry of chlorophenols has received much attention, and many such studies have proposed dominant roles for homolytic and/or heterolytic $\mathrm{Cl}-\mathrm{PhOH}$ bond fission processes under such conditions. ${ }^{18}$ Akai et al ${ }^{19}$ have also compared the IR spectrum of 2-ClPhOH (and various di- and trichlorophenols) in an Ar matrix, pre- and post-UV irradiation, and deduced the formation of cyclopentadienylidenemethanone (CPYM) along with $\mathrm{HCl}$ co-products. Here we report a comprehensive isomer- and, where possible, conformer-selective study of the near UV photochemistry of chlorophenols in the gas phase, using an arsenal of experimental and theoretical methods including (i) electronic spectroscopy of the respective parent molecules, (ii) time-resolved ultrafast pump-probe imaging studies of the evolving excited state population (monitored via the parent ion and the accompanying photoelectrons), (iii) H Rydberg atom photofragment translational spectroscopy (HRAPTS) to monitor $\mathrm{H}$ atom forming channels, (iv) velocity map imaging (VMI) to monitor channels leading to formation of ground $(\mathrm{Cl})$ and spin-orbit excited $\left(\mathrm{Cl}^{*}\right)$ products, $(\mathrm{v})$ time resolved (TR) FTIR emission spectroscopy to monitor vibrationally excited parent molecules and dissociation products like CPYM, $\mathrm{HCl}$ and $\mathrm{CO}$, and, finally, (vi) electronic structure methods to calculate (a) cuts through the ground and first excited state PESs along $R_{\mathrm{O}-\mathrm{H}}$ and $R_{\mathrm{C}-\mathrm{Cl}}$ and for out-ofplane ring distortion towards a prefulvenic structure, and (b) numerous minima and transition states on the ground state PES. These suggest that the greatly reduced $\mathrm{S}_{1}$ state lifetime in isolated syn-2-ClPhOH molecules is attributable to a much enhanced rate of internal 
conversion (IC), facilitated by a (relative) lowering of the adiabatic potential energy upon $\mathrm{C}-$ $\mathrm{Cl}$ bond extension.

\section{Experimental and theoretical methods}

2-, 3- and 4-ClPhOH were each sourced from Sigma-Aldrich and used as supplied. Details regarding the experimental procedures used in Bristol, ${ }^{11,20}$ Warwick, $^{21}$ Oxford ${ }^{22,23}$ and Gifsur-Yvette ${ }^{24,25}$ and of the electronic structure calculations, ${ }^{7}$ have been given previously and are not repeated here. Further details unique to the present study are available as electronic supplementary information (ESI).

\section{Results and Discussion}

\subsection{Excitation spectroscopy}

Room temperature UV absorption spectra of 2-, 3- and 4-ClPhOH and jet-cooled 1+1 resonance enhanced multiphoton ionisation (REMPI) spectra of each isomer in the region of the respective $\mathrm{S}_{1}-\mathrm{S}_{0}$ origins were confirmed as being similar to those reported previously; 9,26,27 these origins and the respective first ionisation potentials are collected in Table I for future reference. Room temperature UV absorption spectra of $2-\mathrm{ClPhOH}$ (in the gas phase and in solution in cyclohexane) and of 3- and 4-ClPhOH (in cyclohexane solution) are shown in the ESI, while figs. 1(a) and 1(b) show jet-cooled 1+1 REMPI spectra of 2- and 3$\mathrm{ClPhOH}$, plotted on a common wavelength scale. The spectrum of $2-\mathrm{ClPhOH}$ is dominated by the $s y n$-conformer - consistent with its greater relative stability. The energy separation between the syn- and anti-conformers of $3-\mathrm{ClPhOH}\left(\mathrm{S}_{0}\right)$, in contrast, is sufficiently small that each shows with comparable intensity in the 1+1 REMPI spectrum. Figure 1 also serves to illustrate the greater width of the syn-2-ClPhOH resonances, consistent with the reported short lifetime of this conformer in its $\mathrm{S}_{1}$ state. ${ }^{13}$ All of the same resonances are evident in the excitation spectra for forming $\mathrm{H}$ atom fragments (monitored via $1(121.6 \mathrm{~nm})+1^{\prime}(365.7 \mathrm{~nm})$ REMPI) though, as shown in the ESI, the relative intensities of the weak anti-2-CIPhOH resonances are reduced.

\subsection{Ultrafast pump-probe studies}


The time evolution of the population following photoexcitation of the various isomers was investigated by monitoring both ions and photoelectrons. Figure 2(a) shows the timeevolving parent $\left(2-\mathrm{ClPhOH}^{+}\right)$ion yield following excitation of $2-\mathrm{ClPhOH}$ with a fs pump pulse centred on the $S_{1}-S_{0}$ band origin $\left(\lambda_{\text {pump }}=278 \mathrm{~nm}\right.$, with a $\sim 500 \mathrm{~cm}^{-1}$ full width half maximum (FWHM) bandwidth) and subsequent probing with a time delayed fs probe pulse centred at $\lambda_{\text {probe }}=243.1 \mathrm{~nm}$. A biexponential fit to this transient (after deconvolving for the finite pump and probe laser pulse durations, the cross-correlation function for which is described using a $120 \mathrm{fs}$ (FWHM) Gaussian) yields decay time constants of $\tau_{1}=160 \pm 30 \mathrm{fs}$ and $\tau_{2}=750 \pm 100 \mathrm{fs}$. An analogous study at $\lambda_{\text {pump }}=267 \mathrm{~nm}$ returned very similar decay constants. As in earlier experiments of this type, ${ }^{28} \lambda_{\text {probe }}$ was chosen to enable REMPI detection of any neutral $\mathrm{H}$ atom photo-products formed by the pump laser pulse. No $\mathrm{H}$ atom signal was detected on the sub-ps timescale of these measurements at either pump wavelength, but prompt $\mathrm{H}$ atom formation was observed following fs laser excitation of 2$\mathrm{ClPhOH}$ at $\lambda_{\text {pump }}=200 \mathrm{~nm}$ (see ESI). By way of contrast, fig. 2(b) shows the time-dependent $2-\mathrm{FPhOH}^{+}$parent ion signal obtained when exciting 2-fluorophenol (2-FPhOH, predominantly if not exclusively its $s y n$-conformer $)$ at its $S_{1}-S_{0}$ origin $\left(\lambda_{\text {pump }}=272 \mathrm{~nm}\right)$ and ionising at $\lambda_{\text {probe }}=243.1 \mathrm{~nm}$. This study returns a $2-\mathrm{FPhOH}\left(\mathrm{S}_{1}\right)$ lifetime $\tau=2.3 \pm 0.2 \mathrm{~ns}$, in reasonable accord with previous estimates from high resolution linewidth studies of the synconformer $\left(\tau=4.6 \pm 0.2 \mathrm{~ns}\right.$ and $2.8 \pm 0.2 \mathrm{~ns}{ }^{29}$ and similar to that found when exciting bare phenol at its $\mathrm{S}_{1}-\mathrm{S}_{0}$ origin. ${ }^{5,28}$ As with phenol, the $2-\mathrm{FPhOH}\left(\mathrm{S}_{1}\right)$ decay time constant was seen to decrease on tuning to shorter excitation wavelengths (e.g. $\tau=1.5 \pm 0.1 \mathrm{~ns}$ at $\lambda_{\text {pump }}=263$ $\mathrm{nm})$.

The temporal decay of the various chlorophenol isomers following excitation to their respective $S_{1}$ states was also investigated by time resolved, $266 \mathrm{~nm}$ pump, $800 \mathrm{~nm}$ (multiphoton) probe photoelectron imaging (TRPEI) methods. Sample images are shown in the ESI. The use of a common pump wavelength necessarily results in population of different $\mathrm{S}_{1}(\mathrm{v})$ levels in each isomer (given the isomer dependent variations in the energy of the $\mathrm{S}_{1}-\mathrm{S}_{0}$ origin), but the effects of such small variations in internal energy must be small compared with the huge variations in $\mathrm{S}_{1}$ lifetime revealed by the TRPEI data shown in figs. 3(a)-3(c). Energetic considerations dictate that a minimum of three $800 \mathrm{~nm}(1.55 \mathrm{eV})$ photons are required to ionise these chlorophenol $\left(\mathrm{S}_{1}\right)$ molecules (see Table 1), and the measured photoelectron images (such as that shown for 2-ClPhOH in fig. 3(a)) and the 
electron kinetic energy distributions derived from such images (see ESI) clearly show a major contribution from 4-photon ionisation. The photoelectrons formed by 3-photon ionisation of 2- $\mathrm{ClPhOH}$ necessarily have low kinetic energy $(E \sim 0.1 \mathrm{eV}$ or less); they also show lower recoil anisotropy than the more energetic electrons from 4-photon ionisation. The latter yield is attributed to excitation via super-excited valence states, with the final photon ionising a manifold of Rydberg states, as reported previously for the case of bare phenol. ${ }^{30}$ The fingerprint of these Rydberg states (starting from $4 s$ state with an assumed quantum defect $\delta$ $=1.05)$ is evident in the image included within fig. 3(a) and is shown in greater detail in the ESI.

The various photoelectron bands for 2- $\mathrm{ClPhOH}$ all show a similar biexponential time decay, characterised by $\tau_{1}=190 \pm 30 \mathrm{fs}$ and $\tau_{2}=700 \pm 100 \mathrm{fs}$, but with very different pre-exponential factors $A_{i}(i=1,2)$. $A_{2}$ declines continuously from $\sim 0.3$ to 0 (relative to $A_{1}=1$ ) as $E_{\mathrm{el}}$ increases to $1.5 \mathrm{eV}$. The two time constants are in excellent agreement with those determined from the ultrafast pump-probe measurements of the parent ion yield (above). Energetic and Franck-Condon considerations imply that the less energetic electrons formed via 4-photon ionisation must arise from regions of lower potential energy (i.e. higher vibrational energy) lower, in fact, than the $\mathrm{S}_{1}$ origin, so the finding that the lower energy electrons show a longer (overall) time constant suggests that the $\tau_{2}=700$ fs decay reflects the final crossing to the $S_{0}$ state.

We return to this topic, and the role of the intramolecular $\mathrm{H}$ bond in facilitating this radiationless transfer in $2-\mathrm{ClPhOH}$, in section 3.8. The decay time constants determined for the $\mathrm{S}_{1}$ states of 3-ClPhOH (fig. 3(b)) and 4-ClPhOH (fig. 3(c)) are $\sim 72$ ps and $\sim 370$ ps, respectively. The latter value agrees reasonably well with that $(\tau=1.0 \pm 0.3 \mathrm{~ns})$ estimated from the widths of individual lines in the $\mathrm{S}_{1}-\mathrm{S}_{0}$ origin band. ${ }^{17}$ The TRPEI data for 4-CIPhOH (fig. 3(c)) also shows an interesting ${ }_{1}$ dependent early time behaviour, with the high/(low) $E_{\mathrm{el}}$ signal showing a decay/(growth) time constant $\tau \sim 800 \mathrm{fs}$. Given that $267 \mathrm{~nm}$ photon absorption prepares $4-\mathrm{ClPhOH}\left(\mathrm{S}_{1}\right)$ molecules with excess $\left(\sim 1500 \mathrm{~cm}^{-1}\right)$ vibrational energy, we assign this short time evolution to vibrational energy redistribution within the $S_{1}$ state. The TRPEI signals for each isomer decline essentially to zero within the accessible time delays, suggesting that the respective $\mathrm{S}_{1}$ states decay to the ground (rather than a long lived triplet) state.

\subsection{Time-of-flight measurements of $\mathrm{H}$ atom products}


HRAPTS studies of the near UV photolysis of 4-ClPhOH at many different wavelengths have been reported previously. ${ }^{11}$ Total kinetic energy release (TKER) spectra derived from timeof-flight (TOF) measurements of the $\mathrm{H}$ atom photofragments (together with the assumption that the partner fragment has chemical formula $\mathrm{ClC}_{6} \mathrm{H}_{4} \mathrm{O}$ and a mass $m=127.55 \mathrm{u}$ ) following excitation on the respective $\mathrm{S}_{1}-\mathrm{S}_{0}$ origin transitions of the syn-isomers of 3-and 2-ClPhOH are shown in figs. 4(a) and 4(b). The former displays several peaks attributable to population of specific vibrational levels of the 3-ClPhO radical in its ground electronic state. The individual peak assignments match closely with those reported recently for the 3-FPhO products formed following excitation to the $\mathrm{S}_{1}(\mathrm{v}=0)$ level of $3-\mathrm{FPhOH}$ and, as in that case, can be attributed to tunnelling under the $\mathrm{S}_{1} / \mathrm{S}_{2} \mathrm{CI}$ facilitated by parent $\mathrm{OH}$ torsional motion. ${ }^{7}$ As for $\mathrm{PhOH}, 3-\mathrm{FPhOH}$, etc, measurements with the electric vector $(\varepsilon)$ of the photolysis laser radiation aligned at different angles $(\theta)$ to the TOF axis reveal no measurable recoil anisotropy for these $\mathrm{H}$ atom fragments. Similarly structured TKER spectra are observed when exciting higher energy resonances within the $\mathrm{S}_{1}-\mathrm{S}_{0}$ manifold, as shown in the ESI. In contrast, excitation on the $\mathrm{S}_{1}-\mathrm{S}_{0}$ origin band of $s y n-2-\mathrm{ClPhOH}$ (or any of the other resonances evident in fig. 1(a)) yields TKER spectra that peak at low TKER and are devoid of any fine structure, as illustrated by fig. 4(b).

TKER spectra derived from $\mathrm{H}$ atom TOF data from photolysis of both 3- and 2-ClPhOH at much shorter wavelengths (below $\sim 230 \mathrm{~nm}$ ) show weakly structured features centred at much higher TKER - as illustrated for the specific case of $\lambda=225 \mathrm{~nm}$ in figs. 4(c) and 4(d). Both show measurable recoil anisotropy. In the case of $3-\mathrm{ClPhOH}$, the signal is greater when $\theta=$ $0^{\circ}$ (i.e. recoil anisotropy parameter, $\beta>0$, implying that these $\mathrm{H}$ atom products recoil preferentially parallel to the parent transition dipole moment) whereas, as in $\mathrm{PhOH}$, the $\mathrm{H}$ atom signal from short wavelength photolysis of $2-\mathrm{ClPhOH}$ is relatively larger when $\theta=90^{\circ}$ (i.e. preferential perpendicular recoil, $\beta<0$ ). Given the different relative stabilities of the syn- and anti-conformers of $2-\mathrm{ClPhOH}$, it is reasonable to assume that the signal in fig. 4(d) is largely from photodissociation of the syn-conformer, while the energy splitting of the ground state syn-and anti-conformers of 3-ClPhOH is presumably too small to significantly degrade the resolution of fig. 4(c). These TKER spectra are reminiscent of those obtained when exciting phenol, and 2- or $3-\mathrm{FPhOH}^{7}$ at similarly short wavelengths and, as in those cases, the structure may be plausibly assigned to short progressions in radical mode $v_{18 \mathrm{~b}}$ (an in-plane $\mathrm{C}-\mathrm{O} / \mathrm{C}-\mathrm{Cl}$ wagging motion in this case). Since both are asymmetrically substituted phenols, we associate the fastest peak in each TKER spectrum to formation of $\mathrm{H}$ atoms in 
association with the partner radical in its zero-point $(\mathrm{v}=0)$ vibrational level. Analysis of TKER spectra of each isomer recorded at many different wavelengths yield the respective bond dissociation energies $D_{0}(s y n-2-\mathrm{ClPhO}-\mathrm{H})=30940 \pm 50 \mathrm{~cm}^{-1}$ and $D_{0}(3-\mathrm{ClPhO}-\mathrm{H})=$ $30500 \pm 50 \mathrm{~cm}^{-1}$. Taken together with the previous determination of $D_{0}(4-\mathrm{ClPhO}-\mathrm{H})=$ $29520 \pm 50 \mathrm{~cm}^{-1}$ (ref. 11) these values serve to illustrate (a) the reduction in $\mathrm{O}-\mathrm{H}$ bond strength caused by introducing an electron rich $\mathrm{Cl}$ atom at the 4- rather than 3-position (i.e. by stabilising the radical product) and (b) the increase in $\mathrm{O}-\mathrm{H}$ bond strength in the syn-2conformer (i.e. the stabilisation of the $\mathrm{S}_{0}$ parent molecule by intramolecular H-bonding).

\subsection{VMI studies of $\mathrm{Cl}$ and $\mathrm{Cl}$ * atom products}

Imaging chlorine atom products from chlorophenols is complicated by the presence of much larger ion signals at $m / z \geq 36$ which we attribute to $\mathrm{C}_{3} \mathrm{H}_{n}^{+}(n=0-3)$ fragment ions; indeed, our previous studies of $4-\mathrm{ClPhOH}$ failed to identify any $\mathrm{Cl}$ or $\mathrm{Cl}^{*}$ products that could be unambiguously attributed to one photon induced dissociation. ${ }^{20}$ In the present work, however, we did succeed in obtaining 'one colour' images of $\mathrm{Cl}$ and $\mathrm{Cl}^{*}$ products from photolysis of 2$\mathrm{ClPhOH}$ at, respectively, $235.33 \mathrm{~nm}$ and $235.21 \mathrm{~nm}$ - the standard wavelengths for $2+1$ REMPI detection of ground $(\mathrm{Cl})$ and spin-orbit excited $\left(\mathrm{Cl}^{*}\right)$ atoms. ${ }^{31}$ As fig. 5 shows, both images are isotropic, though the $\mathrm{Cl}^{*}$ signal is substantially weaker, and the distributions derived therefrom both peak at low TKER $\left(\sim 2000 \mathrm{~cm}^{-1}\right.$, calculated on the basis that the partner fragment has chemical formula $\mathrm{C}_{6} \mathrm{H}_{5} \mathrm{O}$ and a mass $m=93.11 \mathrm{u}$ ).

\subsection{Time resolved FTIR emission spectroscopy}

TR-FTIR methods were used to investigate the emission from vibrationally excited products arising from a room temperature sample of $2-\mathrm{ClPhOH}$ following excitation at three different wavelengths: $266 \mathrm{~nm}, 226 \mathrm{~nm}$ and $193.3 \mathrm{~nm}$. Figure 6 shows a compilation of FTIR emission spectra (in the form of a false colour plot) recorded over the wavenumber range 2000-3100 $\mathrm{cm}^{-1}$ at numerous time delays in the range 0-90 $\mu$ s following photolysis of 2$\mathrm{ClPhOH}$ at $193.3 \mathrm{~nm}$. Three band systems are clearly evident: (i) an intense emission in the 2000-2150 $\mathrm{cm}^{-1}$ range that narrows and blue-shifts with increasing time delay (ending at a centre value of $\sim 2107 \mathrm{~cm}^{-1}$ ), attributable to the $\mathrm{C}=\mathrm{C}=\mathrm{O}$ asymmetric stretch mode of $\mathrm{CPYM}$; (ii) a more persistent feature in the same wavenumber region, centred at $\sim 2140 \mathrm{~cm}^{-1}$ and attributable to $\Delta v=-1$ transitions of CO; and (iii) a richly structured emission in the 2500$3100 \mathrm{~cm}^{-1}$ range which can be assigned to vibrationally excited (but collisionally rotationally 
thermalized) $\mathrm{HCl}$ products - the co-fragment accompanying formation of CPYM. Upon deuteration of the hydroxyl group in 2- $\mathrm{ClPhOH}$, emission in the $\mathrm{HCl}$ region was markedly reduced, but the expected emission from $\mathrm{DCl}$ was obscured by the intense CPYM emission near $2000 \mathrm{~cm}^{-1}$. Qualitatively, at least, this result is consistent with the expectation that $\mathrm{HCl}$ elimination involves the hydroxyl $\mathrm{H}$ atom rather than an $\mathrm{H}$ atom from the ring. Similar emission from rovibrationally excited $\mathrm{CO}$ molecules was reported in an earlier TR-FTIR study of phenol photolysis at $193.3 \mathrm{~nm},{ }^{8}$ and companion electronic structure calculations for a range of isomerization and dissociation reactions on the $\operatorname{PhOH}\left(\mathrm{S}_{0}\right)$ PES (at the G2M//B3LYP/6-311G(d,p) level of theory) identified $\mathrm{CO}$ and $\mathrm{H}_{2}$ eliminations (the latter yielding CPYM as the co-product) as the least endoergic decomposition pathways. The same $\mathrm{HCl}(\Delta v=-1), \mathrm{CO}(\Delta v=-1)$ and CPYM emissions were observed when exciting 2-ClPhOH at $226 \mathrm{~nm}$ and at $266 \mathrm{~nm}$, though comparison of the $\mathrm{HCl}$ contours recorded at early time delays indicates less vibrational excitation in the products formed at the longer excitation wavelengths (see ESI). Figure 7 highlights clear differences between the early time $(\Delta t=4$ us) IR emission from 2-ClPhOH following excitation at (a) $226 \mathrm{~nm}$ and (b) $266 \mathrm{~nm}$. The latter shows additional features in the $3000-3600 \mathrm{~cm}^{-1}$ region which, as fig. 7(c) shows, are attributable to vibrationally excited parent syn-2-ClPhOH molecules. ${ }^{32}$

3-ClPhOH was studied less extensively by TR-FTIR emission spectroscopy, and 4-ClPhOH not at all (due to its substantially lower vapour pressure). The appearance and evolution of the feature attributable to CPYM following $193.3 \mathrm{~nm}$ photoexcitation of $3-\mathrm{ClPhOH}$ is indistinguishable from that observed when exciting 2-ClPhOH at the same wavelength, but analysis of the $\mathrm{HCl}$ emissions suggests that the partner $\mathrm{HCl}$ products carry less vibrational excitation than their counterparts from 2-ClPhOH.

\subsection{Summary of Experimental Findings}

These complementary measurements:

(i) Confirm (and quantify) the previously recognised ${ }^{13}$ sub-ps lifetime of the $\mathrm{S}_{1}$ state of syn-2-ClPhOH. The corresponding excited state lifetimes for 3- and 4-ClPhOH are, respectively, $\sim 2$ and $\sim 3$-orders of magnitude longer. The $\mathrm{S}_{1}$ state of 2$\mathrm{FPhOH}$, in contrast, is found to have a ns lifetime (similar to that of $\mathrm{PhOH}^{28}$ ), 
while previous absorption studies imply that the lifetime of the $\mathrm{S}_{1}$ state of syn-2$\mathrm{BrPhOH}$ is even shorter than that of syn-2-ClPhOH. ${ }^{13}$

(ii) Reveal prompt $\mathrm{O}-\mathrm{H}$ bond fission when exciting all three chlorophenol isomers at short wavelengths (i.e. at energies above the $\mathrm{S}_{1} / \mathrm{S}_{2} \mathrm{CI}$ ). The derived TKER spectra are similar to those obtained when exciting $\mathrm{PhOH}$ at such short wavelengths and are consistent with dissociation on the $\mathrm{S}_{2}\left({ }^{1} \pi \sigma^{*}\right)$ PES. ${ }^{2,7}$ Exciting 3- and 4$\mathrm{ClPhOH}$ at long wavelengths (i.e. on $\mathrm{S}_{1}-\mathrm{S}_{0}$ resonances below the $\mathrm{S}_{1} / \mathrm{S}_{2} \mathrm{CI}$ ) yields some translationally excited $\mathrm{H}$ atoms attributable to $\mathrm{O}-\mathrm{H}$ bond fission by tunnelling through the barrier under the $\mathrm{S}_{1} / \mathrm{S}_{2} \mathrm{CI}$ (more clearly in the case of 3$\mathrm{ClPhOH})$. No corresponding $\mathrm{H}$ atom signal was detected when exciting syn-2$\mathrm{ClPhOH}$ at these energies, thus eliminating such tunnelling as a possible cause of the much enhanced syn-2-ClPhOH$\left(\mathrm{S}_{1}\right)$ loss rate.

(iii) Demonstrate formation of $\mathrm{HCl}, \mathrm{CO}$ and $\mathrm{CPYM}$ following excitation of 2-ClPhOH at 193.3, 226 and $266 \mathrm{~nm}$, as well as vibrationally excited parent molecules at the longest of these wavelengths. $\mathrm{Cl}$ (and $\mathrm{Cl}^{*}$ ) atoms were also detected when exciting at $\sim 235 \mathrm{~nm}$, with isotropic velocity distributions that peak at low TKER. $\mathrm{HCl}, \mathrm{CO}$ and CPYM products were also identified following $193.3 \mathrm{~nm}$ excitation of $3-\mathrm{ClPhOH}$.

The latter products show obvious parallels with those reported following $193.3 \mathrm{~nm}$ photolysis of gas phase $\mathrm{PhOH}$, which have been plausibly interpreted in terms of unimolecular decay of highly vibrationally excited molecules formed following radiationless transfer to the $\mathrm{S}_{0} \mathrm{PES}{ }^{8}$ Analogy with previous studies of chlorobenzene photolysis ${ }^{33}$ led Yamamoto et al. ${ }^{13}$ to suggest intersystem crossing to a ${ }^{3} \pi \sigma^{*}$ state (the equilibrium geometry for which involved an extended $\mathrm{C}-\mathrm{Cl}$ bond length) as the cause of the dramatic reduction in $\mathrm{S}_{1}$ lifetime in the case of syn-2-ClPhOH. Our recent comparative studies of photoinduced halogen (Y) atom loss from the family of 4-YPhOH ( $\mathrm{Y}=\mathrm{I}, \mathrm{Br}$ and $\mathrm{Cl}$ ) molecules, in contrast, identified triplet state participation in the case that $\mathrm{Y}=\mathrm{I}$ only. ${ }^{20} \mathrm{In}$ what follows, we thus look again for singlet state only (i.e. spin conserving) routes to explain the observed photochemistry of the gas phase chlorophenols. We start by considering the various possible fates of chlorophenol molecules following radiationless transfer to the $\mathrm{S}_{0} \mathrm{PES}$, then move on to explore various radiationless transfer routes to the $\mathrm{S}_{0}$ state from higher singlet states.

\subsection{Topology of the $S_{0} P E S$}


The ground state PESs for unimolecular dissociation of 2- and 4-ClPhOH were calculated at the B3LYP/6-31G(d) level of theory (with single-point energy calculations using the larger 6$311+\mathrm{G}(d, p)$ basis $)$ in order to rationalize the loss of $\mathrm{H}_{2}, \mathrm{CO}$ and $\mathrm{HCl}$ fragments. Many of the intermediates and transition states (TSs) are similar or identical to those located in earlier studies of $\mathrm{PhOH}^{8,34}$ and 2-ClPhOH ${ }^{35}$ but, for completeness, all the key stationary points have been located again at a consistent level of theory. Details of these calculations are given in the ESI. Similar dissociation processes have also been described for unimolecular decay of molecular ions of phenol and related species. ${ }^{36}$ The B3LYP density functional theory (DFT) method used here is not quantitative but, within expected error bars of order $5 \mathrm{kcal} \mathrm{mol}^{-1}$ $(\sim 0.2 \mathrm{eV})$, should provide a reasonable description of the relative energies of the various dissociation asymptotes and the transition states joining them. Test calculations using singlereference correlated ab initio methods (as in ref. 8) suggest that these methods may not be more accurate than B3LYP for the present system due to the significant multi-reference character of some of the TSs.

The B3LYP/6-311+G(d,p)//B3LYP/6-31G $(d)$ level of theory used here reproduces the features of the PES for $\mathrm{PhOH}$ dissociation found in previous studies ${ }^{8,34}$ reasonably well. For example, the key TSs leading to loss of $\mathrm{H}_{2}$ or CO (TSs 1 and 14 in ref. 8) lie, respectively, 98.9 and $81.0 \mathrm{kcal} \mathrm{mol}^{-1}$ above the phenol minimum using the present methodology ( $c f .102 .1$ and $75.8 \mathrm{kcal} \mathrm{mol}^{-1}$ in ref. 8). Note that all quoted energies derived in the present work include a correction for zero-point energy using the B3LYP/6-31G(d) wavenumbers. The calculated energy for $\mathrm{H}$ atom loss by $\mathrm{O}-\mathrm{H}$ bond cleavage is also reproduced quite well (81.6 $\mathrm{kcal} \mathrm{mol}^{-1}$, $\mathrm{c}$. $89.1 \mathrm{kcal} \mathrm{mol}^{-1}$ in ref. Error! Bookmark not defined.).

Apart from the $\mathrm{H}$ atoms attributed to tunnelling under the $\mathrm{S}_{1} / \mathrm{S}_{2} \mathrm{CI}$ in 3- and 4-ClPhOH, all of the fragments observed in the long wavelength photolysis of the chlorophenols are attributed to unimolecular decay of vibrationally excited $\mathrm{S}_{0}$ molecules formed by radiationless transfer after electronic excitation. Many minima and connecting TSs are accessible at the photon energies used in the present work; only a relevant subset of these pathways is shown in fig. 8 . Several bond cleavage processes yielding $\mathrm{H}$ or $\mathrm{Cl}$ atoms (plus a partner radical) are identified by the present calculations, with $\mathrm{O}-\mathrm{H}$ bond fission predicted to be the least endoergic $\left(D_{0}(\mathrm{H}-\right.$ $\mathrm{OPhCl})=83.3 \mathrm{kcal} \mathrm{mol}^{-1}$ ) though the $\mathrm{C}-\mathrm{Cl}$ bonds are also predicted to be relatively weak . We also note that the $D_{0}(s y n-2-\mathrm{ClPhO}-\mathrm{H})$ value determined in the companion experimental studies ( $88.5 \mathrm{kcal} \mathrm{mol}^{-1}$ (section 3.3)) reinforces an earlier conclusion ${ }^{8}$ that the methods used in the present calculations are likely to underestimate the $\mathrm{O}-\mathrm{H}$ bond strengths. 
Several molecular elimination processes are also possible and, as fig. 8 shows, the lowestenergy barriers leading to these products in some cases lie below the asymptotes for direct bond cleavage. The variational TSs leading to bond cleavage will be significantly looser than the saddle-point TSs involved in molecular elimination, but the earlier RRKM studies ${ }^{8}$ suggest that the molecular elimination pathways will dominate, at least at lower energies. Four molecular fragments can, in principle, be eliminated yielding relatively low-energy fragments: $\mathrm{H}_{2}, \mathrm{H}_{2} \mathrm{O}, \mathrm{HCl}$ and $\mathrm{CO}$. Loss of $\mathrm{H}_{2}$ from the phenol $\mathrm{OH}$ group and an adjacent $\mathrm{C}-$ $\mathrm{H}$ bond involves barriers $>100 \mathrm{kcal} \mathrm{mol}^{-1}$ and is not shown in fig. 8. Loss of $\mathrm{H}_{2} \mathrm{O}$ with formation of a benzyne derivative is also calculated to involve a rather high barrier labelled TS A in fig. 8. (Note that, in order to avoid overloading fig. 8, this TS is only shown for $\mathrm{H}_{2} \mathrm{O}$ loss from 4-ClPhOH, but a similar TS $\left(\mathbf{A}^{\prime}\right)$ with a very similar barrier exists for $\mathrm{H}_{2} \mathrm{O}$ loss from 2-ClPhOH).

The processes with lower energy barriers involve elimination of $\mathrm{HCl}$ and of $\mathrm{CO}$. For the former, $\mathrm{HCl}$ loss with concerted ring contraction can occur through the (previously identified ${ }^{35}$ ) TS B, to yield a cyclopentadienyl ketene derivative (CPYM) - the calculated energy of which is $E=27.6 \mathrm{kcal} \mathrm{mol}^{-1}$ above the $\mathrm{S}_{0}$ minimum. The structure of TS B (calculated at $E=$ $\left.75.2 \mathrm{kcal} \mathrm{mol}^{-1}\right)$ involves a largely broken $\mathrm{C}-\mathrm{Cl}$ bond $\left(R_{\mathrm{C}-\mathrm{Cl}}=3.17 \AA\right.$ cf. 1.77 in syn-2$\left.\mathrm{ClPhOH}\left(\mathrm{S}_{0}\right)\right)$, with the new $\mathrm{C}-\mathrm{C}$ bond only partly formed $(2.00 \AA$ vs. $1.46 \AA)$. The $\mathrm{C}-\mathrm{O}$ bond length at the TS $(1.23 \AA)$ is closer to that in the product $\left(R_{\mathrm{C}-\mathrm{O}}=1.16 \AA\right)$ than in the starting species $(1.36 \AA)$. Nonetheless, the difference in $\mathrm{C}-\mathrm{O}$ bond length at the TS compared to that in CPYM would be sufficient to account for the observed vibrational excitation of the nascent product. Another possible $\mathrm{HCl}$ loss route involves the higher-energy TS C (at $E=85.3 \mathrm{kcal} \mathrm{mol}^{-1}$ ) after formation of the cyclohexadienone tautomer of $\mathrm{ClPhOH}$ through TS D. TS C also involves concerted $\mathrm{HCl}$ loss and ring contraction, and likewise has a short $\mathrm{C}-\mathrm{O}$ bond length $\left(R_{\mathrm{C}-\mathrm{O}}=1.19 \AA\right)$. $\mathrm{HCl}$ loss from 4-ClPhOH can also occur, since 2and $4-\mathrm{ClPhOH}$ can interconvert through a variety of relatively low-energy multi-step pathways, one of which is shown in fig. 8. From 2-ClPhOH, $\mathrm{H}$ transfer from the $\mathrm{OH}$ group to the adjacent Cl-bearing carbon through TS D forms a cyclohexadienone species. Two subsequent $\mathrm{H}$-atom shifts (TSs $\mathbf{E}$ and $\mathbf{F}$ ) followed by one $\mathrm{Cl}$-atom shift (TS $\mathbf{G}$ ) yields an isomeric cyclohexadienone, which can then convert over the barrier associated with TS $\mathbf{H}$ to 4-ClPhOH. $\mathrm{CO}$ elimination involves formation of a bicyclic species from one of the intermediates along this isomerisation pathway, over TS I. The bicyclic species can then lose CO through TS $\mathbf{J}$. There are several isomers of the bicyclic species, depending on the 
position of the chlorine substituent, but only one (leading to the lowest-energy form of TS $\mathbf{J}$, at $E=81.4 \mathrm{kcal} \mathrm{mol}^{-1}$ ) is shown in fig. 8 .

3- $\mathrm{ClPhOH}$ has been considered here in less detail and, for the sake of clarity, the associated energies are not shown in fig. 8 . The $\mathrm{S}_{0}$ minimum is calculated to lie $0.8 \mathrm{kcal} \mathrm{mol}^{-1}$ above that of syn-2-ClPhOH, and several possible dissociation and isomerisation pathways can be considered. Here, we describe one possible route that could lead ultimately to loss of $\mathrm{HCl}$ and formation of the CPYM product. First, 3-ClPhOH can convert to 5chlorocyclohexadienone $\left(E=17.2 \mathrm{kcal} \mathrm{mol}^{-1}\right)$ through a TS analogous to TSs D and $\mathbf{H}$ (lying at $E=66.6 \mathrm{kcal} \mathrm{mol}^{-1}$ ). In turn, this species can isomerize to the 6-chlorocyclohexadienone species shown in fig. 8 (at $E=23.6 \mathrm{kcal} \mathrm{mol}^{-1}$ ) through a two-step process. First, an $\mathrm{H}$ atom shifts from position 6 to 5 through a TS analogous to TS $\mathbf{G}\left(E=64.9 \mathrm{kcal} \mathrm{mol}^{-1}\right)$ to form a biradical intermediate lying at $E=57.1 \mathrm{kcal} \mathrm{mol}^{-1}$. The latter then undergoes a 5,6 $\mathrm{Cl}$ atom shift through a chloro-analogue of TS $\mathbf{G}\left(E=74.5 \mathrm{kcal} \mathrm{mol}^{-1}\right)$, thereby offering one relatively low-energy process enabling interconversion between 2- and 3-ClPhOH.

In summary, these DFT calculations show that the key TSs for loss of $\mathrm{HCl}$ or $\mathrm{CO}$ from 2-, 3and $4-\mathrm{ClPhOH}$ all lie well below the longest wavelength photon energies used in the present experiments, and below the asymptotes corresponding to $\mathrm{O}-\mathrm{H}$ or $\mathrm{C}-\mathrm{Cl}$ bond cleavage. Suitable isomerisation TSs have also been located at sufficiently low energies to permit rapid interconversion between the isomers prior to dissociation.

\subsection{Radiationless transfer to the $S_{0} P E S$}

Figure 9 displays cuts through the PESs of the ground and first excited singlet states of 2- and 4- $\mathrm{ClPhOH}$ calculated as functions of three nuclear distortions, with a view to identifying possible differences in the non-radiative decay pathways available to the respective $\mathrm{S}_{1}$ molecules. Panels (a) and (d) show cuts along $R_{\mathrm{O}-\mathrm{H}}-$ arguably the most studied dissociation pathway from the $S_{1}$ state of phenol and substituted phenols ${ }^{4,6}$ - with all atoms constrained to lie in the plane. $\mathrm{O}-\mathrm{H}$ bond fission from the $\mathrm{S}_{1}$ state of either isomer would require the molecule to tunnel under the $\mathrm{S}_{1} / \mathrm{S}_{2} \mathrm{CI}$. The magnitude of this barrier (relative to the respective $S_{1}(v=0)$ levels $)$ is calculated to be very similar in the two isomers, so such a mechanism is unlikely to offer an explanation for the orders of magnitude difference in the lifetimes of the $\mathrm{S}_{1}$ states of 2- and 4-ClPhOH. 
Panels (b) and (e) compare the energy profiles for another much studied coordinate when considering internal conversion in benzene derivatives - the out-of-plane ring deformation leading to a low energy $\mathrm{S}_{1} / \mathrm{S}_{0} \mathrm{CI}$ with prefulvenic geometry. ${ }^{37}$ Starting from the respective $\mathrm{S}_{1}$ minima, both 2- and 4-ClPhOH molecules would need to surmount $\sim 1 \mathrm{eV}$ potential barriers in order to access this CI. Again, it appears very improbable that this radiationless pathway could account for the sub-picosecond lifetime of the 2-ClPhOH$\left(\mathrm{S}_{1}\right)$ state.

Panels (c) and (f) explore a third coordinate, the $\mathrm{C}-\mathrm{Cl}$ stretch. The dashed PECs show linear interpolations in internal coordinates (LIICs) between the minima of the diabatic $\mathrm{S}_{1}$ and $\mathrm{S}_{2}$ states (and beyond), calculated with all atoms confined to the $C_{\mathrm{s}}$ ring plane. The symmetry constrained PECs for 2- and 4-ClPhOH are broadly similar, with an obvious minimum (from the diabatic ${ }^{1} \pi \pi^{*}$ state) at $R_{\mathrm{C}-\mathrm{Cl}} \sim 1.78 \AA$, a barrier (the lower cone of the CI between the diabatic $\mathrm{S}_{1}$ and $\mathrm{S}_{2}$ states at $R_{\mathrm{C}-\mathrm{Cl}} \sim 2.1 \AA$ ) and a shallow minimum (associated with the diabatic ${ }^{1} \pi \sigma^{*}{ }_{\mathrm{C}-\mathrm{Cl}}$ state) at longer $R_{\mathrm{C}-\mathrm{Cl}}(\sim 2.6 \AA$ in the case of $2-\mathrm{ClPhOH}$ (fig. 9(c)). Isomer specific differences become much more evident once $C_{\mathrm{s}}$ symmetry constraints are lifted. The solid curves in panels (c) and (f) show the adiabatic $\mathrm{S}_{1}$ PECs obtained by stepping the $\mathrm{C}-\mathrm{Cl}$ bond length and, at each $R_{\mathrm{C}-\mathrm{Cl}}$ value, allowing all other internal degrees of freedom to relax to the minimum energy configuration. Such relaxation has relatively little effect in the case of 4$\mathrm{ClPhOH}\left(\mathrm{S}_{1}\right)$ (fig. 9(f)); the minimum energy PEC still presents a $\sim 1 \mathrm{eV}$ barrier to dissociation from the $\mathrm{S}_{1}$ minimum. The situation with $2-\mathrm{ClPhOH}$ is very different. The calculated minimum energy path on the relaxed $\mathrm{S}_{1}$ PEC in this case is now essentially barrierless (fig. 9(c)). This dramatic reduction in barrier height is achieved by the $\mathrm{C}-\mathrm{Cl}$ bond moving out of the ring plane. The minimum energy pathway involves passage around the $\mathrm{S}_{1} / \mathrm{S}_{2} \mathrm{CI}$ via motion along the $\mathrm{C}-\mathrm{Cl}$ out-of-plane wagging coordinate. This conclusion is confirmed by inspecting the calculated (harmonic) wavenumbers of the normal mode vibrations of $2-\mathrm{ClPhOH}$ at the $\left(C_{\mathrm{s}}\right.$ constrained) $\mathrm{S}_{1}\left({ }^{1} \pi \pi^{*}\right)$ minimum (listed in the ESI), which return an imaginary value for the $\mathrm{C}-\mathrm{Cl}$ out-of-plane wagging motion.

Key to understanding the very different topologies of the adiabatic $S_{1}$ potentials for 2- and 4$\mathrm{ClPhOH}$ is the nature of the diabatic $\mathrm{S}_{2}\left({ }^{1} \pi \sigma^{*}{ }_{\mathrm{C}-\mathrm{Cl}}\right)$ state. The $\sigma^{*}$ orbital is delocalized over the $\mathrm{C}$ and $\mathrm{Cl}$ atoms in the vertical Franck Condon (vFC) region but can acquire dominant $\mathrm{C}$ or $\mathrm{Cl}$ character upon stretching $R_{\mathrm{C}-\mathrm{Cl}}$. The corresponding $\sigma$ orbital will relax in the opposite direction, gaining dominant $\mathrm{Cl}$ or $\mathrm{C}$ character. These two orbitals contain a total of three electrons in the diabatic $\mathrm{S}_{2}$ state. In the case of $4-\mathrm{ClPhOH}$, increasing $R_{\mathrm{C}-\mathrm{Cl}}$ will lead to a 
progressive localisation of the $\sigma^{*}$ orbital on $\mathrm{Cl}$, so the $\sigma$ electrons can be pictured in an $s p^{2}$ orbital on carbon atom 4 . This is favoured because the state then has overall $4-\mathrm{PhOH}^{*}$---- $\mathrm{Cl}$ character (i.e. a $\mathrm{Cl}$ atom and an excited state of the 4-PhOH radical, in which an electron has moved from the $\pi$ system into the $s p^{2}$ hybrid orbital on the carbon atom at the 4-position). Both fragments are neutral. In the case of $2-\mathrm{ClPhOH}$, the same type of configuration will dominate at very large $R_{\mathrm{C}-\mathrm{Cl}}$ but, at intermediate distances, the presence of the intramolecular $\mathrm{O}-\mathrm{H}$--- $\mathrm{Cl}$ hydrogen bond will stabilize the other resonance form, with 2- $\mathrm{PhOH}^{+}$---- $\mathrm{Cl}^{-}$ character, in which the $\sigma^{*}$ orbital is largely on carbon atom 2 and the $\sigma$ electrons are on $\mathrm{Cl}$. Formally, this leads to a negative charge on chlorine, and the phenolyl fragment has a positive charge. The hydrogen bond in this resonance form is very strong (due to the presence of a cationic H-bond donor and an anionic chlorine acceptor). This is enough to counteract the preference for a neutral state, and has the effect of lowering the energy of the $\mathrm{S}_{2}$ state at intermediate values of $R_{\mathrm{C}-\mathrm{Cl}}$ (relative to that in $\left.4-\mathrm{ClPhOH}\right)$. The $\mathrm{S}_{1}\left(\pi \pi^{*}\right)$ state, in contrast, is not strongly affected by the 2- or 4-substitution, so the relative stabilisation of the $\mathrm{S}_{2}$ state in 2-ClPhOH lowers the energy at which it crosses the $\mathrm{S}_{1}$ state and thus leads to the behaviour described.

Notwithstanding the likely uncertainties associated with the energies reported in fig. 8, it is improbable that the $\mathrm{C}-\mathrm{Cl}$ bond strength exceeds the energy of the $\mathrm{S}_{1}(\mathrm{v}=0)$ level. Nonetheless, no fast $\mathrm{Cl}$ atoms were detected when either isomer is excited near its $\mathrm{S}_{1}$ origin. Thus we still need to identify a radiationless decay pathway for 2- $\mathrm{ClPhOH}$ molecules to the $\mathrm{S}_{0}$ state that is facilitated by $\mathrm{C}-\mathrm{Cl}$ bond extension. This we have not explored exhaustively, but fig. 10 shows the geometry of one low energy CI between the adiabatic $\mathrm{S}_{1}$ and $\mathrm{S}_{0} \mathrm{PESs}$, identified (using Gaussian 09 and the $\operatorname{CASSCF}(10,8) / 3-21 \mathrm{G}$ level of theory) along the $\mathrm{H}-\mathrm{Cl}$ elimination coordinate at $R_{\mathrm{C}-\mathrm{Cl}} \sim 4.01 \AA$, which can be accessed from the long range minimum on the adiabatic $\mathrm{S}_{1}$ PES.

\subsection{Summary discussion}

Theory thus provides a rationale for the dramatically reduced lifetime of $\operatorname{syn}-2-\mathrm{ClPhOH}\left(\mathrm{S}_{1}\right)$ molecules ( $c f$. that for 3- or 4-ClPhOH$\left(\mathrm{S}_{1}\right)$ molecules). The relative stability of the syn- and anti-conformers of 2-ClPhOH means that the population of the latter is too low to study in the present experiments, but the foregoing interpretation implies that anti-2- $\mathrm{ClPhOH}\left(\mathrm{S}_{1}\right)$ molecules should display a ns lifetime. Reverting to $s y n-2-\mathrm{ClPhOH}$, we might speculate that the observed biexponential decay revealed by the ultrafast pump-probe studies (section 3.2) 
may provide some measure of the timescales for $S_{1}$ population to evolve from the vFC region to the shallow minimum at extended $R_{\mathrm{C}-\mathrm{Cl}}$, followed by eventual relaxation to the $\mathrm{S}_{0}$ ground state. The reality may be less straightforward however, if the diabatic $S_{1}$ and $S_{2}$ states are sufficiently mixed in the $\mathrm{vFC}$ region that fs excitation prepares a range of states with mixed $\pi \pi^{*} / \pi \sigma^{*}$ character. Such mixing might account for the obvious asymmetry of the lifetime broadened peaks in the 1+1 REMPI spectrum of 2-ClPhOH (fig. 1(a)), though any attempt at validating this suggestion must be complicated by the predicted double minimum (in the $\mathrm{C}-$ $\mathrm{Cl}$ out-of-plane wag coordinate) in the $\mathrm{S}_{1}$ potential.

Extrapolating this theory also offers a rationale for the very different decay rates of $\mathrm{S}_{1}$ state 2$\mathrm{FPhOH}$ and 2-BrPhOH molecules. The carbon-halogen bond in $2-\mathrm{BrPhOH}$ is weaker than in 2- $\mathrm{ClPhOH}$, so it is reasonable to expect that radiationless transfer to the $\mathrm{S}_{0}$ state via initial carbon-halogen bond extension will be at least as effective as in the case of $2-\mathrm{ClPhOH}-$ consistent with the experimentally derived sub-ps lifetime of the $2-\mathrm{BrPhOH}\left(\mathrm{S}_{1}\right)$ state. $^{13}$ (As in chlorophenol, the 4- $\mathrm{BrPhOH}\left(\mathrm{S}_{1}\right)$ state has a much longer lifetime - as demonstrated by the well resolved vibronic structure in the corresponding $1+1$ REMPI spectrum. ${ }^{11}$ ) The $S_{1}$ state of 2-FPhOH, in contrast, has a ns lifetime (recall fig. 2(b)). This, too, is understandable in light of the foregoing theory. The much greater strength of the $\mathrm{C}-\mathrm{F}$ bond will elevate the $\mathrm{S}_{2}\left({ }^{1} \pi \sigma^{*}\right.$ C-F $)$ potential relative to the $\mathrm{S}_{1}\left({ }^{1} \pi \pi^{*}\right)$ minimum, thereby ensuring that the $\mathrm{S}_{1} / \mathrm{S}_{2} \mathrm{CI}$ constitutes a barrier to $\mathrm{C}-\mathrm{F}$ bond extension and closing the possible IC route facilitated by such motion. Consistent with the foregoing, we also note that high resolution spectroscopy studies of 2-FPhOH (syn-conformer) concluded that the $\mathrm{S}_{1}$ state had a double minimum potential (but were not able to identify the relevant out-of-plane coordinate). ${ }^{29}$ It seems unlikely that intramolecular H-bond assisted IC should be restricted solely to the heavier halophenols, and future studies might logically search for similar effects in, for example, 2halosubstituted thiophenols and anilines.

Finally we consider whether the available data offers insights into the relative quantum yields of the various possible decay channels in these and related phenols, and their variation with excitation energy. The various fluorophenols all have similar reported $\mathrm{S}_{1}$ state lifetimes: syn2-FPhOH, $\tau=2.3 \pm 0.2 \mathrm{~ns}$, fig. 2(b)); syn- and anti-3-FPhOH, $\tau=1.9 \pm 0.1$ and $2.7 \pm 0.2 \mathrm{~ns}$, respectively; ${ }^{5} 4-\mathrm{FPhOH}, \tau=1.7 \pm 0.1 \mathrm{~ns}^{5}{ }^{5}$ The reported lifetime for $4-\mathrm{FPhOD}\left(\mathrm{S}_{1}\right)$ molecules is not much longer: $\tau=3.2 \mathrm{~ns}^{38}$ The reported lifetimes for $\mathrm{PhOH}\left(\mathrm{S}_{1}\right)$ and $\operatorname{PhOD}\left(\mathrm{S}_{1}\right)$ molecules are also similar: $2.2 \mathrm{~ns}$ and $13.3 \mathrm{~ns}$, respectively. ${ }^{39}$ Tunnelling estimates for a range of 
phenols suggest that deuterating the $\mathrm{O}-\mathrm{H}$ bond should result in a $\sim 1000$-fold reduction in the barrier penetration rate. ${ }^{6}$ Thus the available experimental data reinforces the expectation that tunnelling under the $\mathrm{S}_{1} / \mathrm{S}_{2}$ CI makes negligible contribution to the decay of $\mathrm{S}_{1}$ state PhOD (and FPhOD) molecules, but that the rate of this tunnelling process is competitive with that for fluorescence and other (slow) IC pathways in the fully hydrogenated analogues.

The calculated 1-D barriers to $\mathrm{O}-\mathrm{H}$ bond fission under the $\mathrm{S}_{1} / \mathrm{S}_{2} \mathrm{CI}$ in 2- and 4-ClPhOH are of similar magnitude, implying a tunnelling rate constant $\sim 10^{8} \mathrm{~s}^{-1}$ ( $c f$. the $>10^{12} \mathrm{~s}^{-1}$ total loss rate constant measured for syn-2- $\mathrm{ClPhOH}\left(\mathrm{S}_{1}\right)$ molecules). Clearly, the $\mathrm{C}-\mathrm{Cl}$ stretch mediated IC mechanism identified in the present work is the dominant decay pathway, and the various product yields will be determined by the respective unimolecular decay rate constants of the resulting highly vibrationally excited parent $\mathrm{S}_{0}$ molecules at the excitation energy of interest. These have not been estimated in the present work, but we can anticipate their relative rates (and their variation with excitation energy) by reference to the earlier study of phenol photolysis. $^{8}$ As in that study, fig. 8 identifies CO elimination (via TSs D, E, F, I and J) as a low energy channel, supplemented in the present case by a rival $\mathrm{HCl}$ elimination channel (via TS B). Guided by the earlier unimolecular rate constant estimates, ${ }^{8}$ we conclude that both should be major channels when exciting at long wavelengths (consistent with the present observations of $\mathrm{CO}, \mathrm{HCl}$ (and its partner product CPYM) in the TR-FTIR studies at $266 \mathrm{~nm}$ ), but that the alternative $\mathrm{O}-\mathrm{H}$ bond fission on the $\mathrm{S}_{0}$ PES must become increasingly important as the excitation wavelength is reduced. $\mathrm{C}-\mathrm{Cl}$ bond extension is identified as the key motion enabling rapid IC following excitation to the $\mathrm{S}_{1}$ state of $s y n-2-\mathrm{ClPhOH}$, but no $\mathrm{Cl}$ atom products are observed at these long wavelengths and the respective dissociation energies (fig. 9) and masses suggest that $\mathrm{C}-\mathrm{Cl}$ bond fission will never be a serious competitor to $\mathrm{O}-\mathrm{H}$ bond fission on the $\mathrm{S}_{0} \mathrm{PES}$ - consistent with our inability to detect anything other than a weak one colour $\mathrm{Cl}$ atom image when exciting at $235 \mathrm{~nm}$. The HRAPTS studies reveal a further (excited state) contribution to the $\mathrm{H}$ atom yield following excitation of all three chlorophenols at energies above the $\mathrm{S}_{1} / \mathrm{S}_{2} \mathrm{CI}$ in the $\mathrm{O}-\mathrm{H}$ stretch coordinate, but the persistence of $\mathrm{CO}, \mathrm{HCl}$ and CPYM emissions when exciting syn-2-ClPhOH at $226 \mathrm{~nm}$ and both syn-2-ClPhOH and 3- $\mathrm{ClPhOH}$ at $193.3 \mathrm{~nm}$ indicates that competitive IC routes to the $\mathrm{S}_{0}$ PES persist at much higher excitation energies.

\section{Associated content}


Additional experimental details relating to the time resolved FTIR emission studies; further details regarding the computational methods employed; UV absorption spectra of 2-, 3- and 4-chlorophenol; comparisons between the 1+1 REMPI and H atom PHOFEX spectra of 2and $3-\mathrm{ClPhOH}$ when exciting near the respective $\mathrm{S}_{1}-\mathrm{S}_{0}$ origins; time resolved $\mathrm{H}^{+}$fragment and parent ion yield data following $200 \mathrm{~nm}$ excitation of 2-ClPhOH ; selected time resolved photoelectron images following $266 \mathrm{~nm}$ excitation of 2-ClPhOH and their analysis; TKER spectra derived from $\mathrm{H}$ atom PTS measurements at several different wavelengths near the $\mathrm{S}_{1}-$ $\mathrm{S}_{0}$ origins of 2- and 3- $\mathrm{ClPhOH} ; \mathrm{HCl}$ product vibrational distributions deduced from analysis of FTIR emission spectra following 2-ClPhOH photolysis at 266, 226 and $193 \mathrm{~nm}$; calculated harmonic wavenumbers of the normal mode vibrations of 2-ClPhOH at the $\mathrm{C}_{\mathrm{s}}$ constrained minimum energy geometry of the $\mathrm{S}_{1}\left({ }^{1} \pi \pi^{*}\right)$. This material is available free of charge via the Internet at http://pubs.acs.org.

\section{Corresponding author:}

mike.ashfold@bris.ac.uk; tel.+44(0)1179288312

\section{Notes}

The authors declare no competing financial interest.

\section{Acknowledgements}

MNRA, JNH and GH are grateful to EPSRC for funding (Programme Grants EP/G00224X and EP/L005913). MNRA, AMW, DKZ, GS and BS also acknowledge financial support from the Marie Curie Initial Training Network ICONIC (contract agreement no. 238671). DJH and GMR acknowledge EPSRC for doctoral and postdoctoral funding, respectively, while VGS is grateful to EPSRC for an equipment grant (EP/J007153) and the Royal Society for a University Research Fellowship. Parts of the research leading to the present results have benefitted from funding via LASERLAB-EUROPE (contract agreement no. 228334, EC Seventh Framework Programme). 


\section{Table I}

$\mathrm{S}_{1}-\mathrm{S}_{0}$ band origins and adiabatic first ionisation potentials of 2-, 3- and 4-chlorophenol.

\begin{tabular}{|l|c|c|}
\hline & $\mathrm{S}_{1}-\mathrm{S}_{0}$ origin $/ \mathrm{cm}^{-1}$ [ref.] & I.P.(adiab) $/ \mathrm{eV}$ [ref.] \\
\hline 2-ClPhOH, syn & $35892\left[{ }^{13}\right]$ & $\sim 8.9\left[{ }^{27}\right]$ \\
\hline 2-ClPhOH, anti & $35702\left[{ }^{13}\right]$ & \\
\hline 3-ClPhOH, syn & $35769\left[^{15}\right]$ & $8.65\left[{ }^{15}\right]$ \\
\hline 3-ClPhOH, anti & $35889\left[^{15}\right]$ & $8.68\left[{ }^{15}\right]$ \\
\hline & & \\
\hline 4-ClPhOH & $34811\left[^{11}\right]$ & $8.44\left[{ }^{10}\right]$ \\
\hline
\end{tabular}




\section{Figure Captions}

\section{Figure 1}

Jet-cooled 1+1 REMPI spectra of (a) 2-ClPhOH and (b) 3-ClPhOH, with peak assignments from refs. ${ }^{13},{ }^{15}$ and ${ }^{16}$.

\section{Figure 2}

Parent ion transient signals for (a) 2- $\mathrm{ClPhOH}$ and (b) 2-FPhOH following fs pulsed laser excitation at their respective $\mathrm{S}_{1}-\mathrm{S}_{0}$ band origins and time-delayed ionisation with a second $\mathrm{fs}$ pulse at $243.1 \mathrm{~nm}$.

\section{Figure 3}

Photoelectron transients for (a) 2-, (b) 3- and (c) 4-ClPhOH following fs excitation at $266 \mathrm{~nm}$ and time-delayed ionisation by absorption of multiple $800 \mathrm{~nm}$ photons. The false colour plot in (a) shows the velocity (vertical axis) dependent yields and temporal decay behaviour (horizontal axis), while the two traces in (a) highlight the differing time dependence of two (arrowed) components within the photoelectron yield with $E_{\mathrm{el}}=0.15$ and $0.45 \mathrm{eV}$.

\section{Figure 4}

TKER spectra derived from $\mathrm{H}$ atom TOF spectra recorded following nanosecond pulsed laser excitation of (a) syn-3-ClPhOH and (b) syn-2-ClPhOH at the respective $\mathrm{S}_{1}-\mathrm{S}_{0}$ band origins. TKER spectra obtained from $\mathrm{H}$ atom TOF spectra measured following excitation of 3- and 2$\mathrm{ClPhOH}$ at $225 \mathrm{~nm}$ are shown in (c) and (d), respectively.

\section{Figure 5}

TKER distributions derived from one colour VMI images of the $\mathrm{Cl}$ and $\mathrm{Cl}^{*}$ atoms (shown in the insets) following excitation of 2-ClPhOH at (a) $235.33 \mathrm{~nm}$ and (b) $235.21 \mathrm{~nm}$. The photolysis laser in each case was polarised vertically in the plane of the image (as shown by the double headed arrows).

\section{Figure 6}

False colour plot showing IR emission spectra (in the range $2000-3100 \mathrm{~cm}^{-1}$ ) recorded as a function of time delay (over the range $0<\Delta t<90 \mu \mathrm{s}$ ) following $193.3 \mathrm{~nm}$ photolysis of a 20 mTorr sample of 2-ClPhOH. 


\section{Figure 7}

IR emission spectra in the range $2500-3800 \mathrm{~cm}^{-1}$ recorded at $\Delta t=4 \mu$ s following excitation of a $20 \mathrm{mT}$ Trr sample of 2-ClPhOH at (a) $226 \mathrm{~nm}\left(5 \mathrm{~cm}^{-1}\right.$ resolution) and (b) $266 \mathrm{~nm}\left(20 \mathrm{~cm}^{-1}\right.$ resolution). Trace (c) depicts the relevant region of the 2- $\mathrm{ClPhOH}$ absorption spectrum.

\section{Figure 8}

Schematic computed (B3LYP/6-311+G(d,p)//B3LYP/6-31G(d)) PES for isomerisation and dissociation of $\mathrm{ClPhOH}\left(\mathrm{S}_{0}\right)$ molecules. The horizontal red line indicates the (experimental) energy of the $\mathrm{S}_{1}(v=0)$ level. (To aid comparison with ref. ${ }^{8}$, all energies are reported in kcal $\mathrm{mol}^{-1}$, but can readily be converted to $\mathrm{eV}$ using the equivalence $1 \mathrm{eV}=23.06 \mathrm{kcal} \mathrm{mol}^{-1}$ ).

\section{Figure 9}

Cuts through the ground and first excited singlet PESs of 2-ClPhOH ((a)-(c)) and 4-ClPhOH ((d)-(f)) plotted as functions of $R_{\mathrm{O}-\mathrm{H}}$, with all atoms constrained to lie in the ring plane ((a) and (d)), out-of-plane deformation ((b) and (e)) and $R_{\mathrm{C}-\mathrm{Cl}}((\mathrm{c})$ and (f)). The excited state PECS in the latter case are shown with (dashed line) and without (solid line) the constraint of $\mathrm{C}_{\mathrm{s}}$ symmetry.

\section{Figure 10}

Geometry of a low energy CI identified between the adiabatic $\mathrm{S}_{1}$ and $\mathrm{S}_{0}$ states of 2-ClPhOH at $R_{\mathrm{C}-\mathrm{Cl}} \sim 4.01 \AA$. 
Figure 1

a)

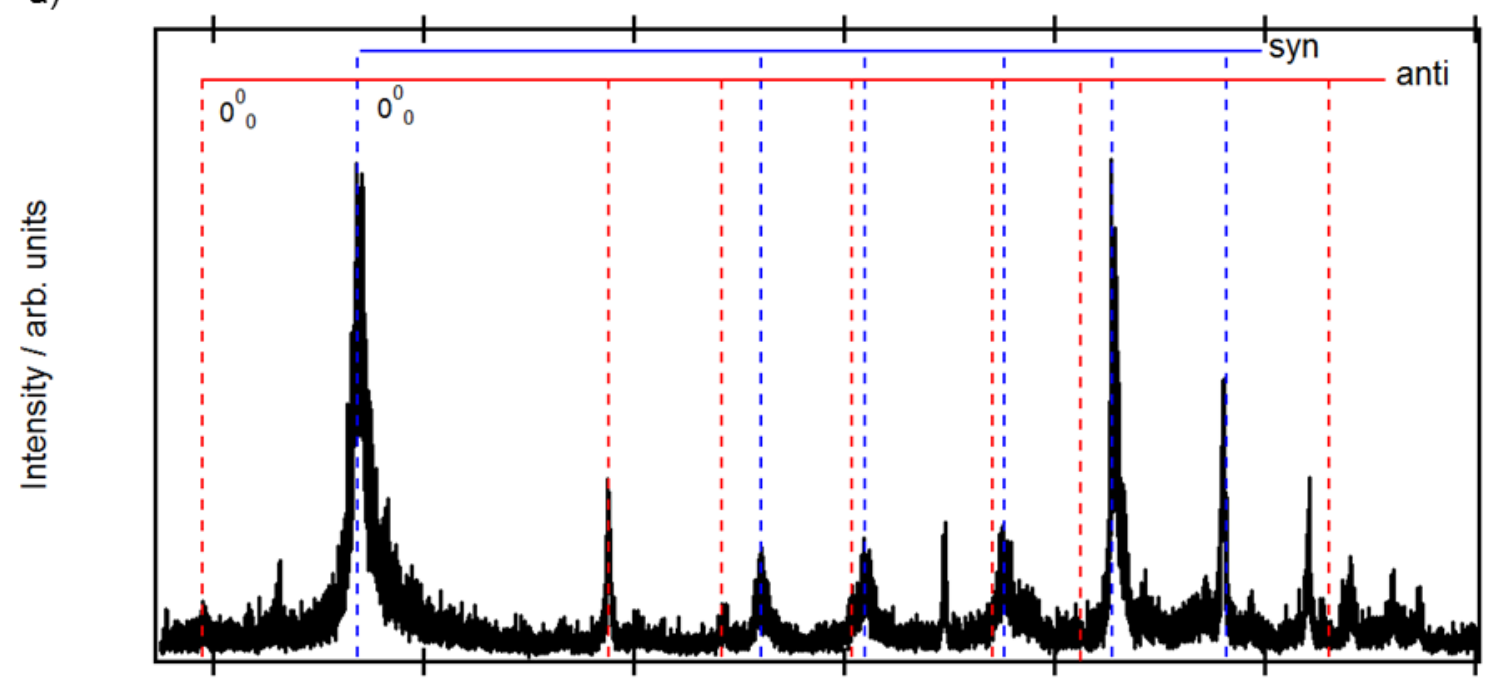

b)

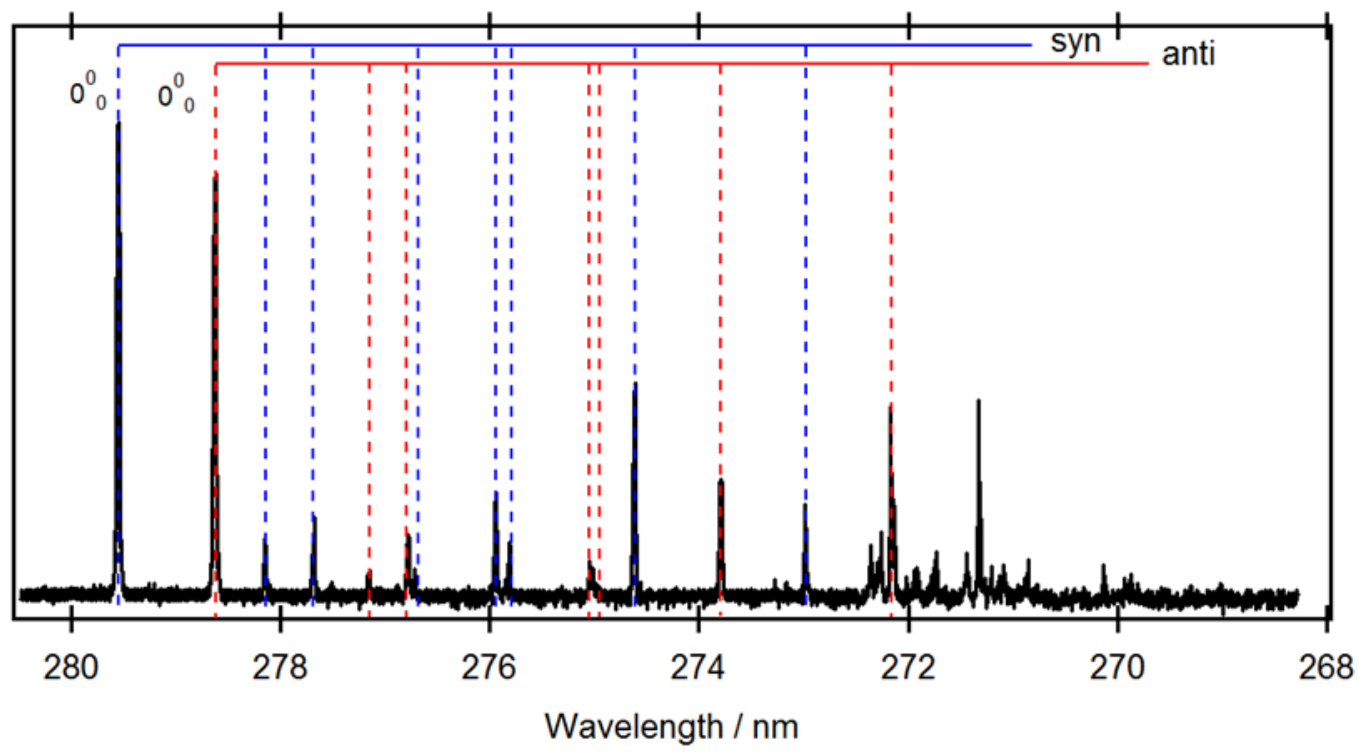


Figure 2
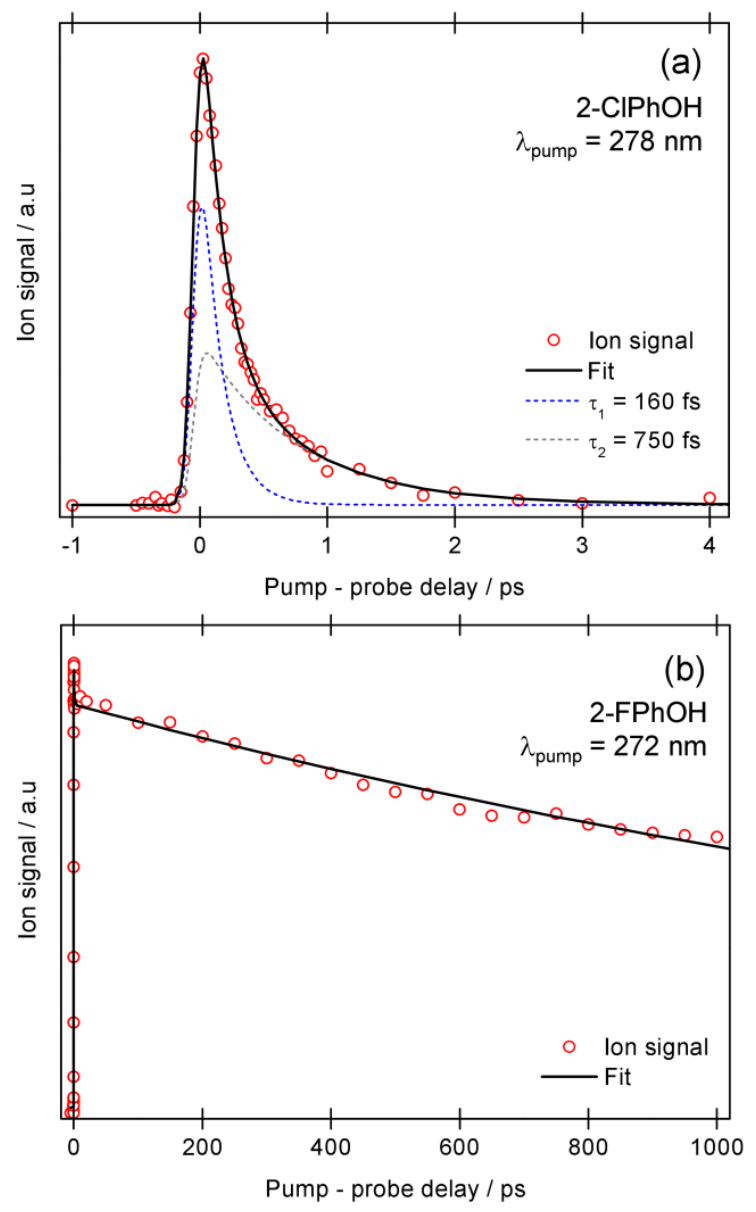
Figure 3
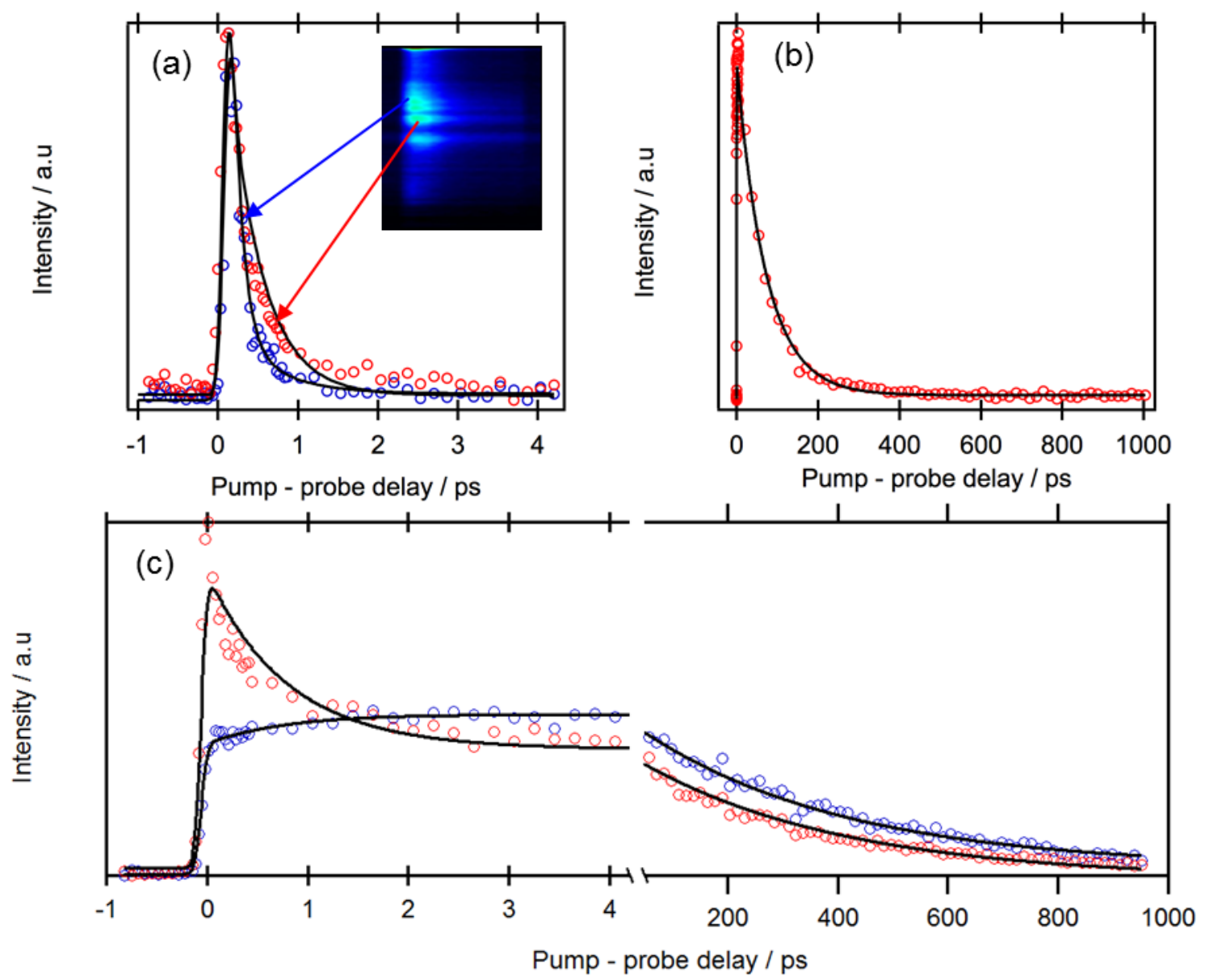
Figure 4

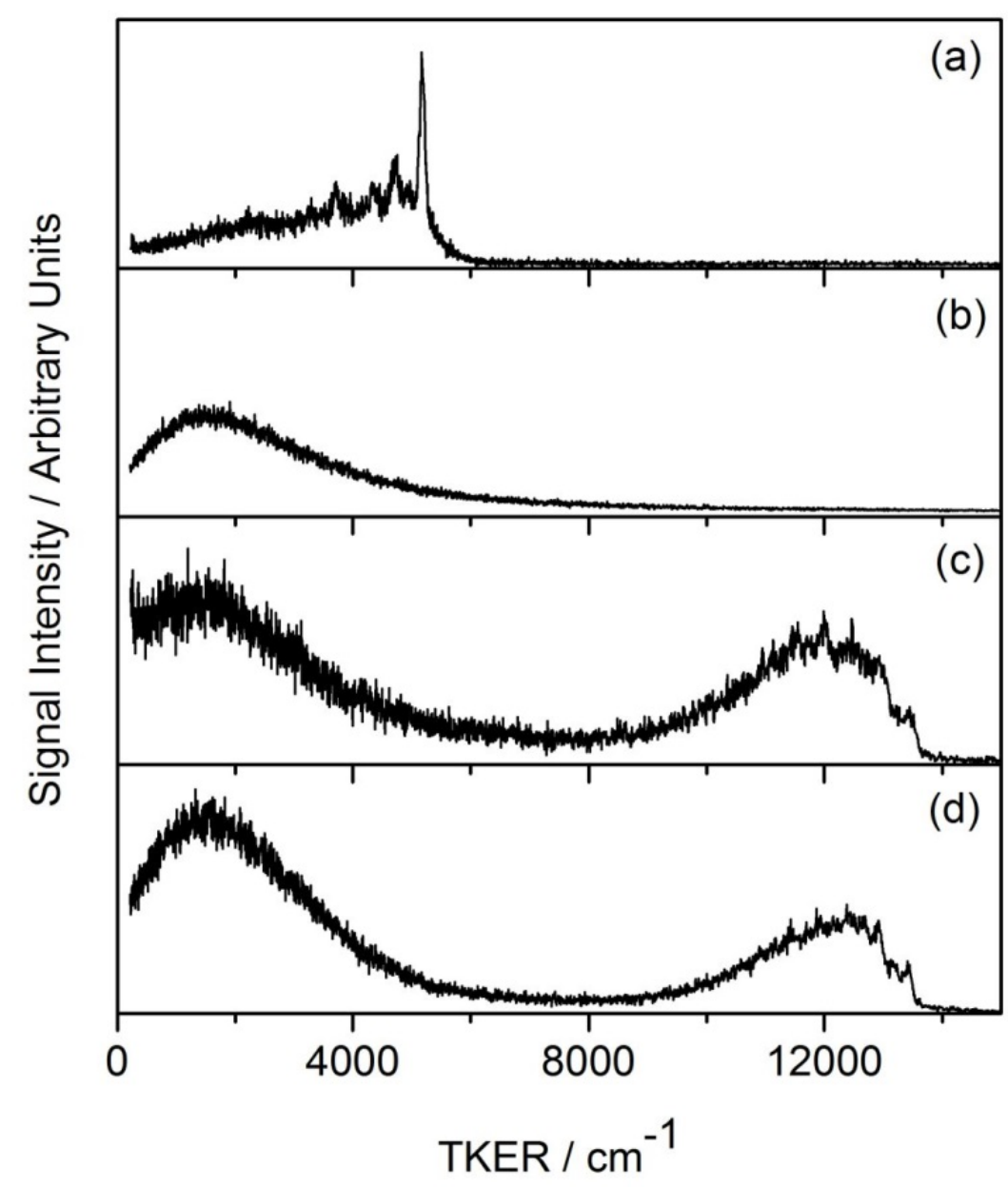


Figure 5

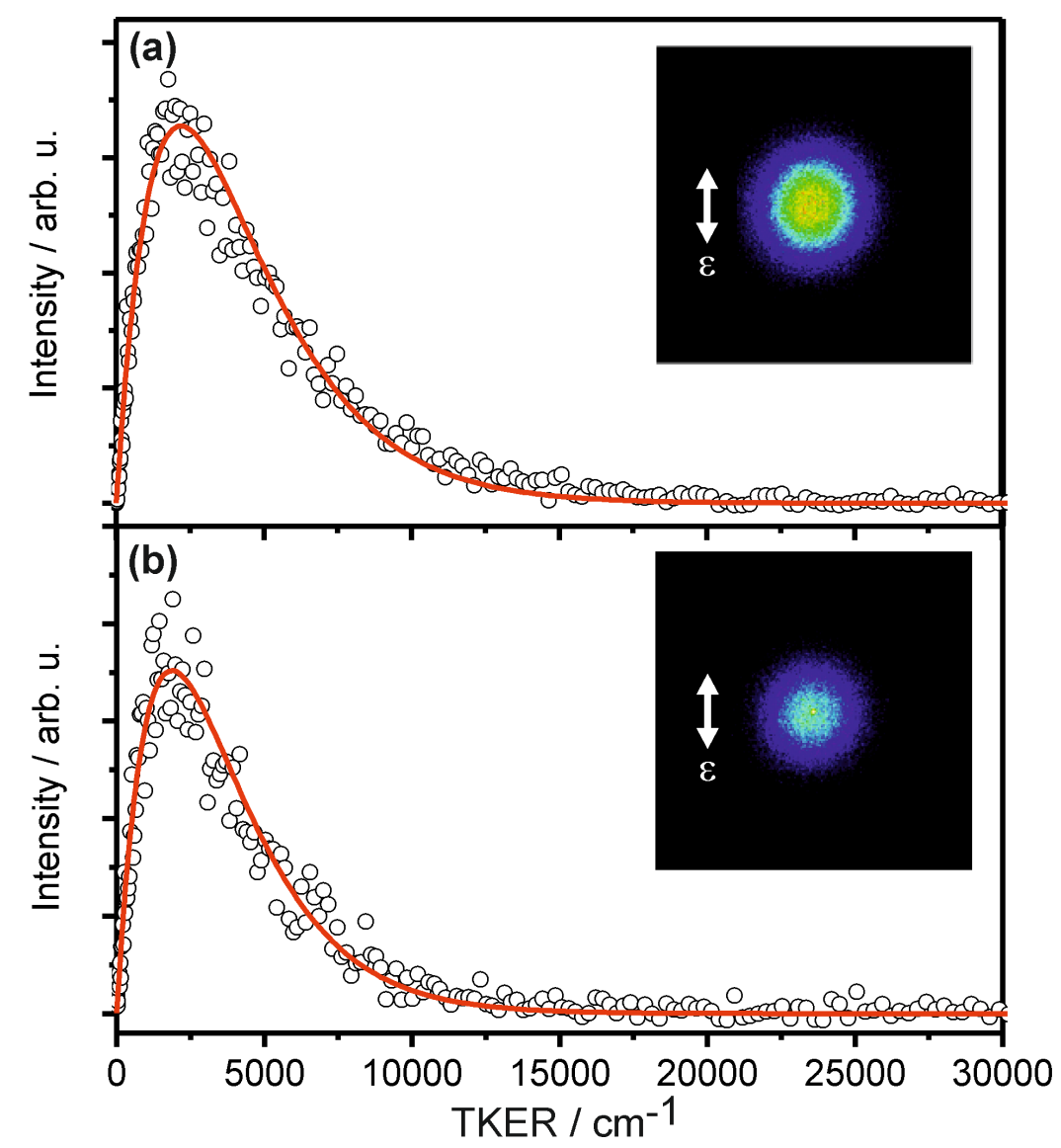


Figure 6

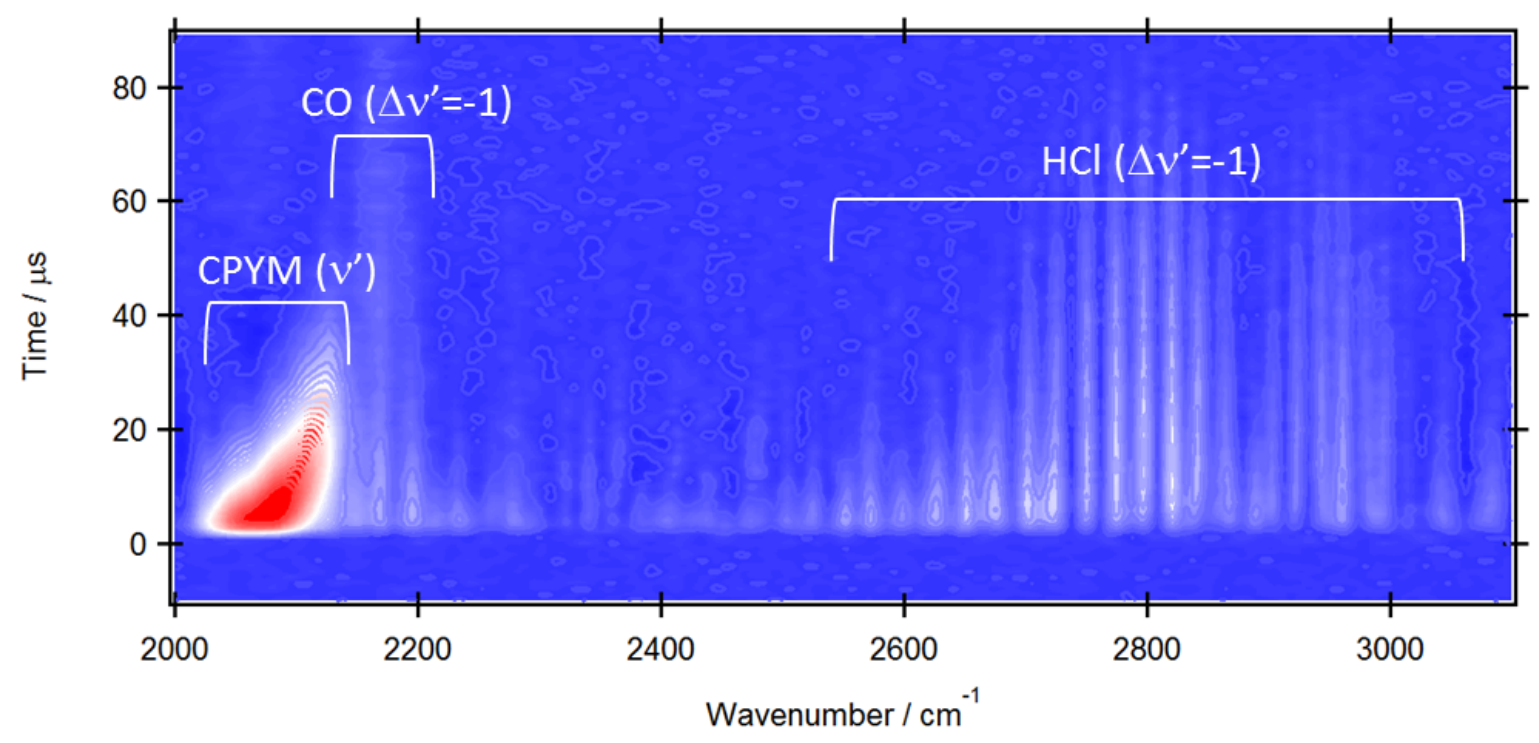


Figure 7

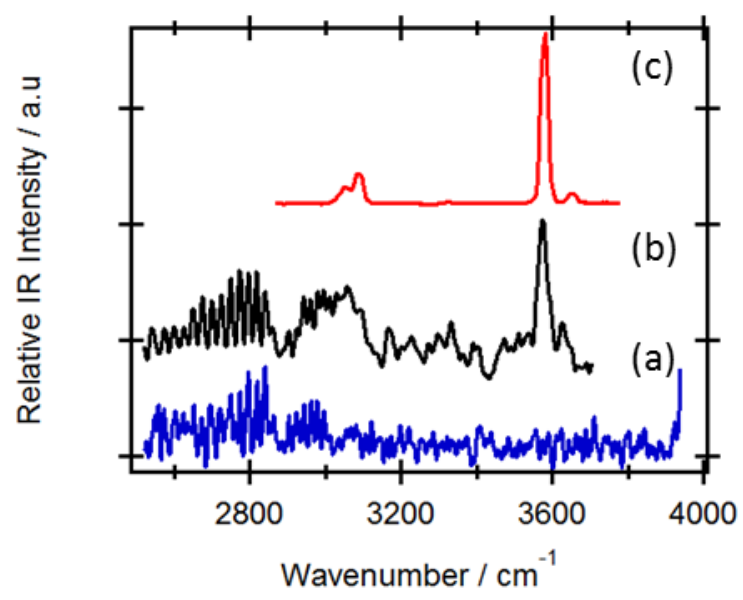


Figure 8

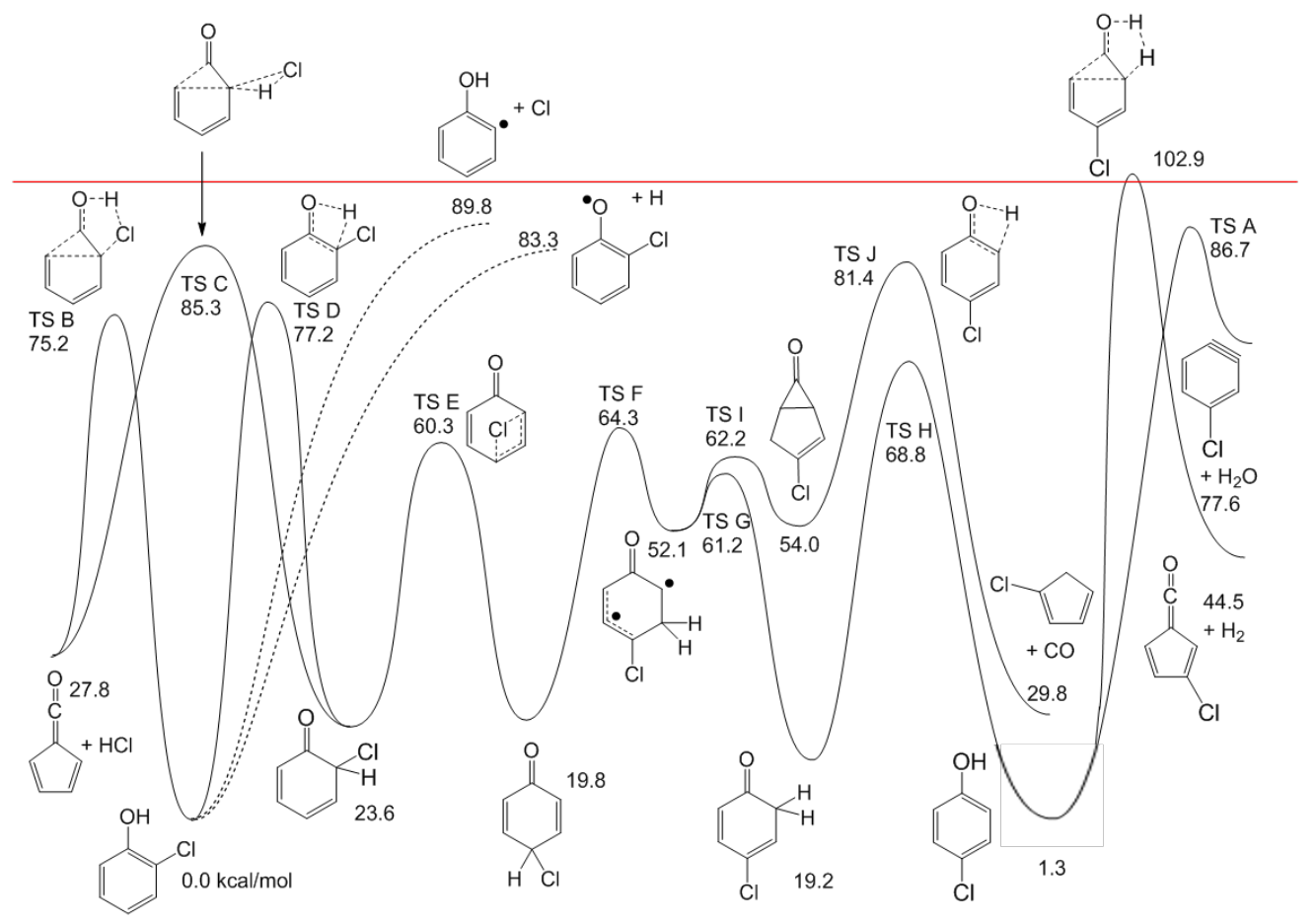


Figure 9
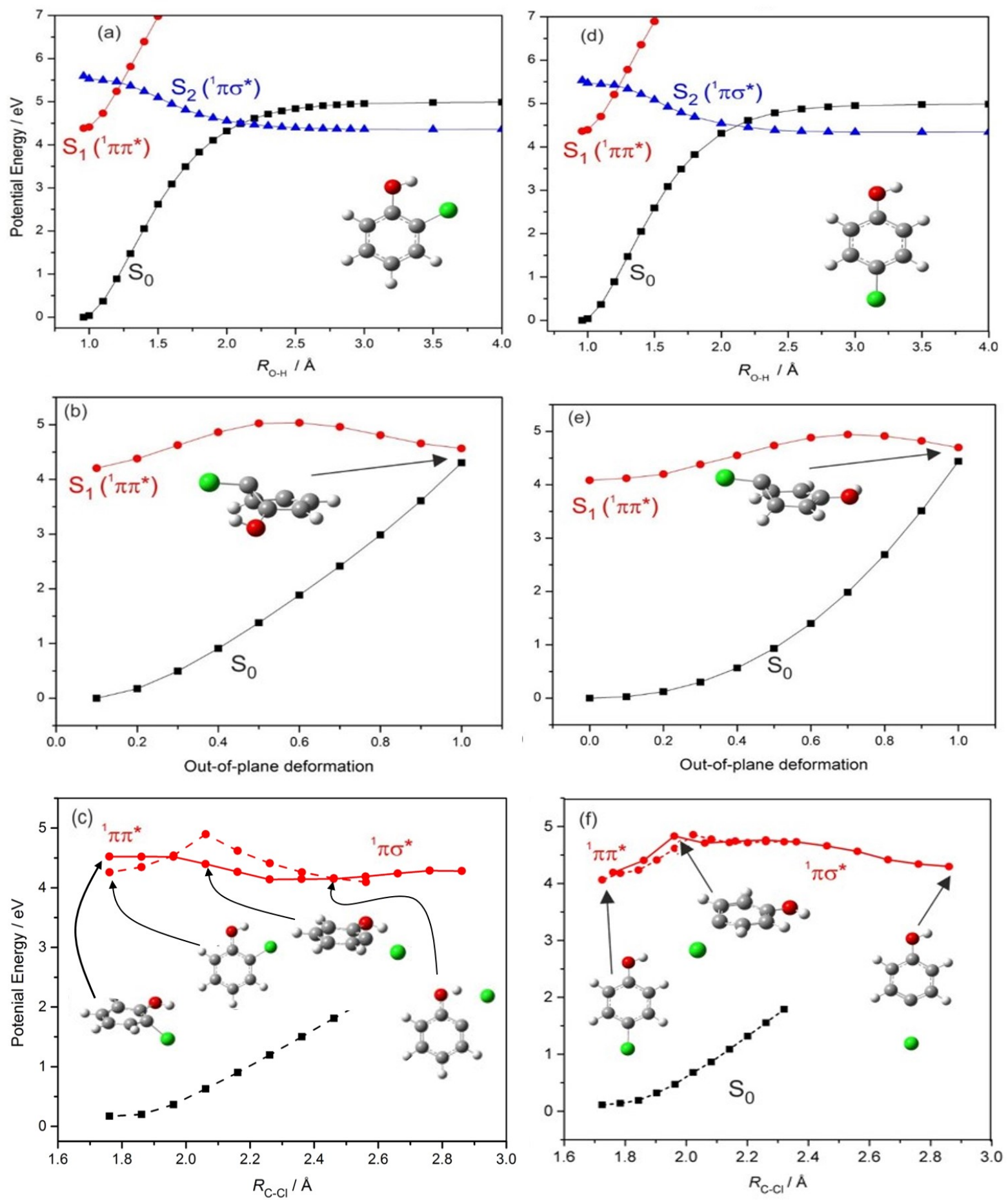
Figure 10

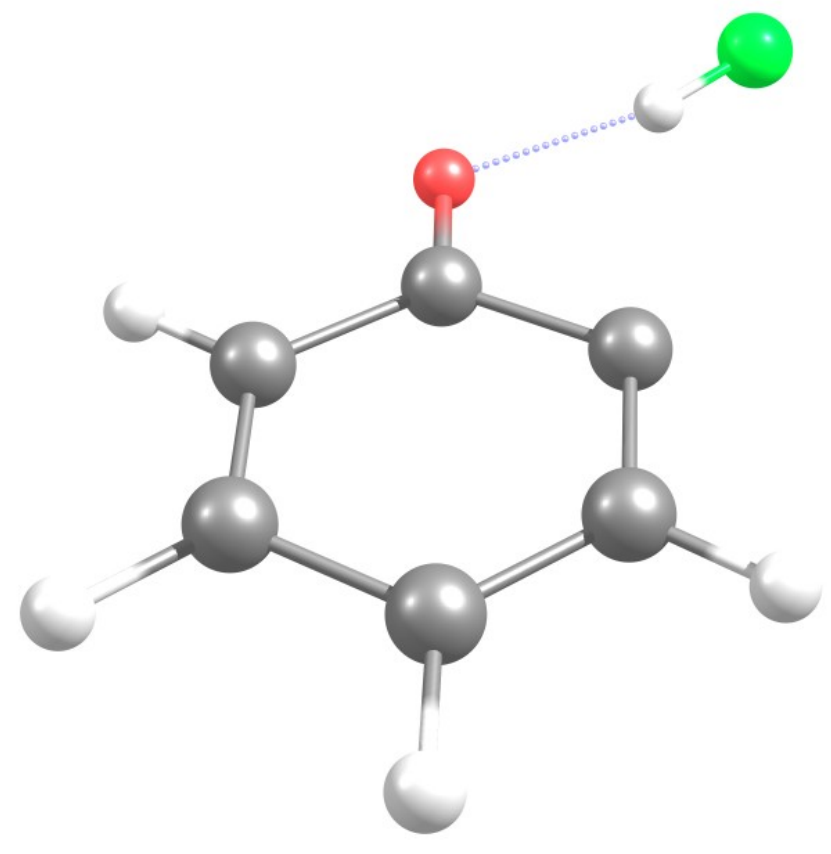




\section{References}

(1) Tseng, C.-M.; Lee, Y. T.; Ni, C.-K. H Atom Elimination from the Pi Sigma* State in the Photodissociation of Phenol. J. Chem. Phys. 2004, 121, 2459-2461.

(2) Nix, M. G. D.; Devine, A. L.; Cronin, B.; Dixon, R. N.; Ashfold, M. N. R. High Resolution Photofragment Translational Spectroscopy Studies of the near Ultraviolet Photolysis of Phenol. J. Chem. Phys. 2006, 125, 133318 - 133331.

(3) Sobolewski, A. L.; Domcke, W.; Dedonder-Lardeux, C.; Jouvet, C. Excited-State Hydrogen Detachment and Hydrogen Transfer Driven by Repulsive $1 \pi \sigma^{*}$ States: A New Paradigm for Nonradiative Decay in Aromatic Biomolecules. Phys. Chem. Chem. Phys. 2002, 4, 1093-1100.

(4) Dixon, R. N.; Oliver, T. A. A.; Ashfold, M. N. R. Tunnelling under a Conical Intersection: Application to the Product Vibrational State Distributions in the UV Photodissociation of Phenols. J. Chem. Phys. 2011, 134, 194303 - 194313.

(5) Pino, G. A.; Oldani, A. N.; Marceca, E.; Fujii, M.; Ishiuchi, S.-I.; Miyazaki, M.; Broquier, M.; Dedonder, C.; Jouvet, C. Excited State Hydrogen Transfer Dynamics in Substituted Phenols and Their Complexes with Ammonia: П $\pi^{*}-\Pi \sigma^{*}$ Energy Gap Propensity and Ortho-Substitution Effect. J. Chem. Phys. 2010, 133, 124313-124325.

(6) Karsili, T. N. V.; Wenge, A. M.; Harris, S. J.; Murdock, D.; Harvey, J. N.; Dixon, R. N.; Ashfold, M. N. R. O-H Bond Fission in 4-Substituted Phenols: S1 State Predissociation Viewed in a Hammett-like Framework. Chem. Sci. 2013, 4, 2434 2446. 
(7) Karsili, T. N. V; Wenge, A. M.; Marchetti, B.; Ashfold, M. N. R. Symmetry Matters: Photodissociation Dynamics of Symmetrically versus Asymmetrically Substituted Phenols. Phys. Chem. Chem. Phys. 2014, 16, 588-598.

(8) Tseng, C.-M.; Lee, Y. T.; Lin, M.-F.; Ni, C.-K.; Liu, S.-Y.; Lee, Y.-P.; Xu, Z. F.; Lin, M. C. Photodissociation Dynamics of Phenol. J. Phys. Chem. A 2007, 111, 9463-9470.

(9) Imhof, P.; Kleinermanns, K. Dispersed Fluorescence Spectra of P-Chlorophenol. Phys. Chem. Chem. Phys. 2002, 4, 264-270.

(10) Huang, J.; Lin, J. L.; Tzeng, W. B. Mass Analyzed Threshold Ionization Spectroscopy of the $35 \mathrm{Cl}$ and $37 \mathrm{Cl}$ Isotopomers of P-Chlorophenol and Isotope Effect. Chem. Phys. Lett. 2006, 422, 271-275.

(11) Devine, A. L.; Nix, M. G. D.; Cronin, B.; Ashfold, M. N. R. Near-UV Photolysis of Substituted Phenols, I: 4-Fluoro-, 4-Chloro- and 4-Bromophenol. Phys. Chem. Chem. Phys. 2007, 9, 3749-3762.

(12) Oikawa, A.; Abe, H.; Mikami, N.; Ito, M. Rotational Isomers of Meta-Substituted Phenols and Beta-Naphthol Studied by Electronic Spectra in Supersonic Free Jets. $J$. Phys. Chem. 1984, 88, 5180-5186.

(13) Yamamoto, S.; Ebata, T.; Ito, M. Rotational Isomers of O-Chlorophenol and Their Different Emission Properties. J. Phys. Chem. 1989, 93, 6340-6345.

(14) Oikawa, A.; Abe, H.; Mikami, N.; Ito, M. Electronic Spectra and Ionisation Potentials of Rotational Isomers of Several Disubstituted Benzenes. Chem. Phys. Lett. 1985, 116, $50-54$. 
(15) Cockett, M. C. R.; Takahashi, M.; Okuyama, K.; Kimura, K. REMPI Threshold Photoelectron Spectra of the Cis and Trans Rotational Isomers of Jet-Cooled MChlorophenol. Chem. Phys. Lett. 1991, 187, 250-256.

(16) Nakagawa, S.; Matsushita, Y.; Suzuki, T.; Ichimura, T. Resonance Enhanced Multiphoton Ionization and Time-of-Flight Mass Spectra of Jet-Cooled 3Chlorophenol Dimer. J. Mol. Struct. 2005, 779, 68-71.

(17) Böhm, M.; Ratzer, C.; Schmitt, M. The Structure of P-Chlorophenol and Barrier to Internal OH Rotation in the S1-State. J. Mol. Struct. 2006, 800, 55-61.

(18) Rayne, S.; Forest, K.; Friesen, K. J. Mechanistic Aspects Regarding the Direct Aqueous Environmental Photochemistry of Phenol and Its Simple Halogenated Derivatives. A Review. Environ. Int. 2009, 35, 425 - 437.

(19) Akai, N.; Kudoh, S.; Takayanagi, M.; Nakata, M. Photoreaction Mechanisms of 2Chlorophenol and Its Multiple Chloro-Substituted Derivatives Studied by LowTemperature Matrix-Isolation Infrared Spectroscopy and Density-Functional-Theory Calculations. Photochem. Photobiol. 2001, 146, 49-57.

(20) Sage, A. G.; Oliver, T. A. A.; King, G. A.; Murdock, D.; Harvey, J. N.; Ashfold, M. N. R. UV Photolysis of 4-Iodo-, 4-Bromo-, and 4-Chlorophenol: Competition between C$\mathrm{Y}(\mathrm{Y}=$ Halogen $)$ and O-H Bond Fission. J. Chem. Phys. 2013, 138, $164318-164330$.

(21) Wells, K. L.; Perriam, G.; Stavros, V. G. Time-Resolved Velocity Map Ion Imaging Study of NH(3) Photodissociation. J. Chem. Phys. 2009, 130, $074308-074313$.

(22) Hancock, G.; Heard, D. E. Time-Resolved FTIR Emission Studies of Photochemical Reactions. Adv. Photochem. 1993, 18, 1-65. 
(23) Hancock, G.; Morrison, M.; Saunders, M. Vibrational Relaxation of NO (v = 1-16) with NO, N2O, NO2, He and Ar Studied by Time-Resolved Fourier Transform Infrared Emission. Phys. Chem. Chem. Phys. 2009, 11, 8507-8515.

(24) Poisson, L.; Nandi, D.; Soep, B.; Hochlaf, M.; Boggio-Pasqua, M.; Mestdagh, J.-M. A Roaming Wavepacket in the Dynamics of Electronically Excited 2-Hydroxypyridine. Phys. Chem. Chem. Phys. 2014, 16, 581-587.

(25) Spighi, G.; Gaveau, M.-A.; Mestdagh, J.-M.; Poisson, L.; Soep, B. Gas Phase Dynamics of Triplet Formation in Benzophenone. Phys. Chem. Chem. Phys. 2014, 16, $9610-9618$.

(26) Tseplin, E. E.; Tseplina, S. N.; Tuimedov, G. M.; Khvostenko, O. G. Identification of Excited Singlet States of Chlorophenol Isomers. Opt. Spectrosc. 2008, 105, 327-332.

(27) Tseplin, E. E.; Tseplina, S. N.; Tuimedov, G. M.; Khvostenko, O. G. Photoelectron and UV Absorption Spectroscopy for Determination of Electronic Configurations of Negative Molecular Ions: Chlorophenols. J. Electron Spectros. Relat. Phenomena 2009, 171, 37-46.

(28) Roberts, G. M.; Chatterley, A. S.; Young, J. D.; Stavros, V. G. Direct Observation of Hydrogen Tunneling Dynamics in Photoexcited Phenol. J. Phys. Chem. Lett. 2012, 3, $348-352$.

(29) Remmers, K.; Meerts, W. L.; Zehnacker-Rentien, A.; Le Barbu, K.; Lahmani, F. Structural Information on the S0 and S1 State of O-Fluorophenol by Hole Burning and High Resolution Ultraviolet Spectroscopy. J. Chem. Phys. 2000, 112, 6237 - 6244. 
(30) Schick, C. P.; Weber, P. M. Ultrafast Dynamics in Superexcited States of Phenol. J. Phys. Chem. A 2001, 105, 3725-3734.

(31) Arepalli, S.; Presser, N.; Gordon, R. J. Detection of Cl Atoms and HCl Molecules by Resonantly Enhanced Multiphoton Ionisation. Chem. Phys. Lett. 1985, 118, 88-92.

(32) Shin, D. N.; Hahn, J. W.; Jung, K.; Ha, T. Study of the Cis and Trans Conformers of 2Halophenols Using Coherent Anti-Stokes Raman Spectroscopic and Quantum Chemical Methods. Chem. Phys. Lett. 1998, 29, 245-249.

(33) Nagaoka, S.; Takemura, T.; Baba, H.; Koga, N.; Morokuma, K. Ab Initio Study on the Low-Lying Triplet States of Chlorobenzene. J. Phys. Chem. 1986, 90, 759-763.

(34) Xu, Z. F.; Lin, M. C. Ab Initio Kinetics for the Unimolecular Reaction C6H5OH --> CO + C5H6. J. Phys. Chem. A 2006, 110, 1672-1677.

(35) Altarawneh, M.; Dlugogorski, B. Z.; Kennedy, E. M.; Mackie, J. C. Quantum Chemical and Kinetic Study of Formation of 2-Chlorophenoxy Radical from 2Chlorophenol: Unimolecular Decomposition and Bimolecular Reactions with $\mathrm{H}, \mathrm{OH}$, Cl, and O2. J. Phys. Chem. A 2008, 112, 3680-3692.

(36) Le, H. T.; Flammang, R.; Gerbaux, P.; Bouchoux, G.; Nguyen, M. T. Ionized Phenol and Its Isomers in the Gas Phase. J. Phys. Chem. 2001, 105, 11582-11592.

(37) Lasorne, B.; Bearpark, M. J.; Robb, M. A.; Worth, G. A. Controlling S 1 / S 0 Decay and the Balance between Photochemistry and Photostability in Benzene : A Direct Quantum Dynamics Study. J. Phys. Chem. A 2008, 112, 13017-13027. 
(38) Ratzer, C.; Nispel, M.; Schmitt, M. Structure of 4-Fluorophenol and Barrier to Internal -OH Rotation in the S1-State. Phys. Chem. Chem. Phys. 2003, 5, 812-819.

(39) Spangenberg, D.; Schmitt, M.; Ratzer, C.; Jochen, K. The Structure of Phenol in the S 1 -State Determined by High Resolution UV-Spectroscopy. Chem. Phys. 2002, 283, $153-169$. 